\title{
Iso-Migrastatin congeners from Streptomyces platensis and generation of a glutarimide polyketide library featuring the dorrigocin, lactimidomycin, migrastatin, and NK30424 scaffolds
}

\author{
Jianhua Ju, ${ }^{1}$ Si-Kyu Lim, ${ }^{1}$ Hui Jiang, ${ }^{1}$ Jeong-Woo Seo, ${ }^{1}$ Ben Shen ${ }^{1,2, *}$ \\ ${ }^{1}$ Division of Pharmaceutical Sciences and ${ }^{2}$ Department of Chemistry, University of Wisconsin- \\ Madison, Madison, Wisconsin 53705, USA. \\ Email: bshen@pharmacy.wisc.edu
}

\section{Supporting Information}

General Experimental Procedures. ${ }^{1} \mathrm{H}$ and ${ }^{13} \mathrm{C}$ NMR spectra were recorded at $25{ }^{\circ} \mathrm{C}$ on Varian Unity Inova 500 instruments operating at $500 \mathrm{MHz}$ for ${ }^{1} \mathrm{H}$ and $125 \mathrm{MHz}$ for ${ }^{13} \mathrm{C}$ nuclei. ${ }^{1} \mathrm{H}$ and ${ }^{13} \mathrm{C}$ NMR chemical shifts were referenced to residual solvent signals: $\delta_{\mathrm{H}} 7.27$ and $\delta_{\mathrm{C}} 77.23$ for $\mathrm{CDCl}_{3}$, and $\delta_{\mathrm{H}} 3.31$ and $\delta_{\mathrm{C}} 49.15$ for $\mathrm{MeOH}-d_{4} \cdot{ }^{1} \mathrm{H}-{ }^{1} \mathrm{H}$ COSY,${ }^{1} \mathrm{H}-{ }^{1} \mathrm{H}$ TOCSY (mixing time $=80$ $\mathrm{ms})$, HMQC $\left({ }^{1} J_{\mathrm{CH}}=140 \mathrm{~Hz}\right)$, and $\mathrm{gHMBC}\left({ }^{2-3} J_{\mathrm{XH}}=8.0 \mathrm{~Hz}\right)$ were performed using standard VARIAN pulse sequences. Electrospray ionization-mass spectrometry (ESI-MS) and LC-MS were carried out on an Agilent 1100 HPLC-MSD SL quadrupole mass spectrometer equipped with both orthogonal pneumatically assisted electrospray and atmospheric pressure chemical ionization sources. High-resolution MS analyses were acquired on an IonSpec HiResMALDI FT-Mass spectrometer with a 7 tesla superconducting magnet. A saturated solution of 2,5-dihydroxybenzoic acid in methanol was used for matrix preparation, and the spectra were peak-matched using $\mathrm{m} / \mathrm{z}$ $273.03936\left(\left[2 \mathrm{M}-2 \mathrm{H}_{2} \mathrm{O}+\mathrm{H}\right]^{+}\right)$as a reference peak. Optical rotations were measured in $\mathrm{CHCl}_{3}$ on a Perkin-Elmer 241 instrument at the sodium D line $(589 \mathrm{~nm})$.

HPLC was carried out on a Varian system equipped with Prostar 210 pumps and a photodiode array (PDA) detector. Unless otherwise stated, the mobile phase used comprises of buffer A (15\% $\mathrm{CH}_{3} \mathrm{CN}$ in $\mathrm{H}_{2} \mathrm{O}$ containing $0.1 \%$ HOAc) and buffer $\mathrm{B}\left(80 \% \mathrm{CH}_{3} \mathrm{CN}\right.$ in $\mathrm{H}_{2} \mathrm{O}$ containing $0.1 \%$ HOAc). Analytical HPLC and LC-MS was conducted using a Prodigy ODS-2 column $(150 \times 4.6$ $\mathrm{mm}, 5 \mu \mathrm{m}$, Phenomenex, Torrance, CA) eluted with a linear gradient of $100 \%$ buffer A and $0 \%$ buffer B to $20 \%$ buffer A and $80 \%$ buffer B over 20 min, followed by 5 min at $20 \%$ buffer A and $80 \%$ buffer B at a flow rate of $1.0 \mathrm{~mL} / \mathrm{min}$ with UV detection at $205 \mathrm{~nm}$. Semi-preparative HPLC was conducted using a C18 column $(250 \times 10 \mathrm{~mm}, 5 \mu \mathrm{m}$, Microsob, Varian) eluted with a linear gradient of $80 \%$ buffer A and $20 \%$ buffer B to $10 \%$ buffer A and $90 \%$ buffer B over 20 min, followed by $10 \mathrm{~min}$ at $10 \%$ buffer $\mathrm{A}$ and $90 \%$ buffer $\mathrm{B}$ at a flow rate of $2.5 \mathrm{~mL} / \mathrm{min}$ with UV detection at $205 \mathrm{~nm}$.

Silica gel 60A (200-425 mesh, Fisher Chemical) was used for flash column chromatography. Amberlite XAD-4, XAD-16, and Diaion HP-20 resins were purchased from Sigma. Crude fermentation extracts, fractions obtained during isolation, compounds finally purified, and reaction mixtures were all monitored by either analytical HPLC or TLC on E. Merck silica gel-60F plates using $\mathrm{CHCl}_{3} / \mathrm{MeOH}$ (9:1) or EtOAc/Hexane (7:3) as developing solvents and iodide as visualizing agent.

Examination of the metabolite profiles of Streptomyces platensis NRRL18993 under different fermentation conditions by HPLC and LC-MS analyses. It is well known that the culture conditions (e.g. medium composition, aeration, culture vessel, temperature, $\mathrm{pH}$, etc.) can affect the secondary metabolite profiles of the microorganism. The relative abundance of each component in the mixture of metabolites obtained from S. platensis cultures was found to be variable, depending upon the culture conditions. Our work has been focusing on further optimizing the culture condition to improve the titers of the whole set of metabolites. The general fermentation 
procedure utilized was a two-stage process. Spore suspension $(50 \mu \mathrm{L})$ of $S$. platensis was inoculated into $50 \mathrm{~mL}$ seed medium in a $250-\mathrm{mL}$ flask. The seed culture was incubated on a rotary shaker at $250 \mathrm{rpm}$ and $28{ }^{\circ} \mathrm{C}$ for $30-48 \mathrm{hr}$. The resultant seed culture $(2.5 \mathrm{~mL}$, i.e., $5 \%$ of the production medium) was inoculated into $50 \mathrm{~mL}$ production medium in a 250 -mL flask, which was incubated on a rotary shaker at $250 \mathrm{rpm}$ and $28{ }^{\circ} \mathrm{C}$ for $1.5-10$ days. The seed medium consisted of $2 \%$ glycerol, $2 \%$ dextrin, $1 \%$ soytone peptone, $0.3 \%$ yeast extract, $0.2 \%\left(\mathrm{NH}_{4}\right)_{2} \mathrm{SO}_{4}$, and $0.2 \%$ $\mathrm{CaCO}_{3}, \mathrm{pH}$ 7.0. The production medium contained the same ingredients as those in seed medium but with additional $20-150 \mathrm{~g} / \mathrm{L}$ resins. Both the seed and production media were sterilized for 30 min at $121^{\circ} \mathrm{C}$ in an autoclave.

Metabolite titers were optimized by altering the seed culture, amount of adsorbent resins supplemented, duration of fermentation time, and level of oxygen supplied. Highest yields were obtained by the combination of (a) relatively young seed culture (30 hr), (b) production medium supplemented with high percentage of resins, (c) relatively short fermentation time, and (d) reduced oxygen supply. Thus, no adverse effect on $S$. platensis growth was observed upon supplementation to the production medium with $2 \%-15 \%(\mathrm{w} / \mathrm{v})$ XAD-16 or $2 \%-7 \%(\mathrm{w} / \mathrm{v}) \mathrm{HP}-20$ resins. While 10 is the major metabolite during the course of 4 to 10 day fermentation, the relative abundance of the other congeners (12-19) to 10 increases dramatically when the fermentation is terminated in 1.5-2 days. Increasing the volume of the production medium in a fixed size flask, thereby reducing the relative level of dissolving oxygen often resulted in an increased amount of 12-19 relative to 10. Further restriction of dissolving oxygen by covering the flask with alumina foil afforded 17-19 as the predominant metabolites. In summary, the highest yields for 10 and 12-19 were obtained when $50 \mathrm{~mL}$ production medium in a $250-\mathrm{mL}$ flask supplemented with $15 \%$ XAD-16 or $7 \% \mathrm{HP}-20$ resins was cultured for 42-48 hr (SFigure-1).

Large-scale fermentation, isolation, and structure elucidation of $\mathbf{1 0}$ and its new congeners 12-19. Seed medium $(50 \mathrm{~mL})$ in a $250-\mathrm{mL}$ flask was inoculated with spores of S. platensis and incubated on a rotary shaker at $250 \mathrm{rpm}$ and $28{ }^{\circ} \mathrm{C}$ for $30 \mathrm{hr}$. The resultant seed culture $(25 \mathrm{~mL})$ was then inoculated into production medium $(600 \mathrm{~mL}$ containing $70 \mathrm{~g} / \mathrm{L}$ XAD-16 resins $)$ in a $2-\mathrm{L}$ flask, which was incubated on a rotary shaker at $250 \mathrm{rpm}$ and $28{ }^{\circ} \mathrm{C}$ for 2 days. The combined production culture broth $(7 \mathrm{~L})$ was filtered through gauze sponges to capture the XAD-16 resins. The resins were washed with Milli-Q $\mathrm{H}_{2} \mathrm{O}$, dried at room temperature, and eluted with anhydrous ethanol. The ethanol extract was evaporated under reduced pressure to yield an oily residue. The residue was first analyzed by HPLC-UV (PDA) and LC-ESI-MS to confirm the presence of the various congeners of 10. Although they can survive during fermentation and be stabilized in $\mathrm{H}_{2} \mathrm{O}$ upon absorption to resins, 10 and its congeners 12-19 undergo rapid rearrangement in aqueous solution. They are stable in most organic solvents such as $\mathrm{CHCl}_{3}$, EtOAc, hexane, and absolute ethanol at room temperature. Consequently, isolation of these metabolites was performed mainly by repeated silica gel flash column chromatography using two different solvent systems $\left(\mathrm{CHCl}_{3} / \mathrm{MeOH}\right.$ and $\left.\mathrm{EtOAc} / \mathrm{hexane}\right)$.

The oily residue was initially applied on a silica gel flash column $(3.8 \times 45 \mathrm{~cm})$, eluted with a $\mathrm{CHCl}_{3} / \mathrm{MeOH}$ (10:0-9:1) gradient, roughly yielding six fractions (A-F), on the basis of analytical HPLC. Fraction A was subjected to silica gel flash column chromatography $(3.8 \times 45 \mathrm{~cm})$ using a $\mathrm{CHCl}_{3} / \mathrm{MeOH}$ (10:0-9.7:0.3) gradient elution to afford A1 (containing mainly 10) and A2 (containing 10 and 12). Fraction A1 was further purified by silica gel flash column chromatography $(3.8 \times 45 \mathrm{~cm})$ using a EtOAc/hexane (4:6-8:2) gradient elution, giving pure compound $10(550 \mathrm{mg})$. Fraction A2 was separated repeatedly by series of silica gel flash column chromatography $(2.5 \times 30 \mathrm{~cm}, 1.9 \times 30 \mathrm{~cm}, 1.3 \times 30 \mathrm{~cm})$, eluted with a $\mathrm{CHCl}_{3} / \mathrm{MeOH}(10: 0-$ 9.7:0.3) or a EtOAc/hexane (4:6-8:2) gradient to afford pure 12 (30 mg). Similarly, further separation of fraction $\mathrm{B}$ upon elution with a $\mathrm{CHCl}_{3} / \mathrm{MeOH}$ (10:0-9.6:0.4) or a EtOAc/Hexane (4:6-9:1) gradient led to pure $\mathbf{1 7}(230 \mathrm{mg})$ and $\mathbf{1 8}(35 \mathrm{mg})$, of fraction $\mathrm{C}$ upon elution with a $\mathrm{CHCl}_{3} / \mathrm{MeOH}(10: 0-9.5: 0.5)$ or a EtOAc/hexane (5:5-9:1) gradient essentially provided pure 13 $(65 \mathrm{mg})$, and of fraction D upon elution with a $\mathrm{CHCl}_{3} / \mathrm{MeOH}$ (10:0-9.4:0.6) or a EtOAc/hexane 
(5:5-10:0) gradient resulted in $\mathbf{1 4}(70 \mathrm{mg})$ and $\mathbf{1 9}(45 \mathrm{mg})$ in pure form and a fraction D3 (30 $\mathrm{mg})$ that showed a single broad peak from analytical HPLC but contained both $\mathbf{1 5}$ and $\mathbf{1 9}$ as evidenced by ${ }^{13} \mathrm{C}$ NMR spectral data. Attempts in obtaining high purity form of $\mathbf{1 5}$ were unsuccessful due to its relative low abundance and the very close polarity between $\mathbf{1 5}$ and 19. However, it was possible to prepare two batch of samples enriched in $\mathbf{1 5}$ and $\mathbf{1 9}$ at different ratio (approximate 1:3 and 3:1), which enabled us to solve the structure of 15 via analyses of 1D and 2D NMR and MS spectra. Due to its extremely low abundance, 16 was only detected by LC-ESI-MS but not purified (Sfigure 1). It should be pointed out that the yields reported are isolated yields for $\mathbf{1 0}$ and its congeners. Given the difficulty in their purification, these yields most likely are underestimated, and their actual titers in S. platensis should be even higher.

\section{Structure elucidation of compounds 12-19.}

16, 17-Didehydro-isomigrastatin (12): Colorless oil; $[\alpha]^{25}{ }_{\mathrm{D}}+123.9^{\circ}\left(c 0.18, \mathrm{CHCl}_{3}\right) ;{ }^{1} \mathrm{H}$ NMR, see STable 1; ${ }^{13} \mathrm{C}$ NMR, see STable 3; selected COSY and gHMBC correlations, see SFigure 2; ESI-MS (-), $m / z$ 486.1 ([M-H $\left.]^{+}\right)$; ESI-MS (+), $m / z$ 488.2 $\left([\mathrm{M}+\mathrm{H}]^{+}\right), 510.1\left([\mathrm{M}+\mathrm{Na}]^{+}\right) ; \mathrm{HR}-$ MALDI-MS (+), $m / z 510.2500\left([\mathrm{M}+\mathrm{Na}]^{+}\right)\left(\right.$calcd 510.2468 for $\left.\left[\mathrm{C}_{27} \mathrm{H}_{37} \mathrm{O}_{7} \mathrm{~N} \mathrm{Na}\right]^{+}\right)$.

17-Hydroxy-isomigrastatin (13): Colorless oil; $[\alpha]^{25}+140.0^{\circ}\left(c 0.10, \mathrm{CHCl}_{3}\right) ;{ }^{1} \mathrm{H}$ NMR, see STable 1; ${ }^{13} \mathrm{C}$ NMR, see STable 3; selected COSY and gHMBC correlations, see SFigure 2; ESIMS (-), $m / z 504.2\left([\mathrm{M}-\mathrm{H}]^{+}\right)$; ESI+MS $(+), m / z 506.1\left([\mathrm{M}+\mathrm{H}]^{+}\right), 528.0\left([\mathrm{M}+\mathrm{Na}]^{+}\right)$; HR-MALDIMS $(+), m / z 528.2550\left([\mathrm{M}+\mathrm{Na}]^{+}\right)\left(\right.$calcd 528.2573 for $\left.\left[\mathrm{C}_{27} \mathrm{H}_{39} \mathrm{O}_{8} \mathrm{~N} \mathrm{Na}\right]^{+}\right)$.

8-Desmethyl-isomigrastatin (14): Colorless oil; $[\alpha]^{25}{ }_{\mathrm{D}}+83.0^{\circ}\left(c 0.10, \mathrm{CHCl}_{3}\right) ;{ }^{1} \mathrm{H}$ NMR, see STable 1; ${ }^{13} \mathrm{C}$ NMR, see STable 3; selected COSY and gHMBC correlations, see SFigure 2; ESIMS (-), $m / z 474.2\left([\mathrm{M}-\mathrm{H}]^{+}\right)$; ESI-MS $(+), m / z 476.0\left([\mathrm{M}+\mathrm{H}]^{+}\right), 498.0\left([\mathrm{M}+\mathrm{Na}]^{+}\right)$; HR-MALDIMS $(+), m / z 498.2476\left([\mathrm{M}+\mathrm{Na})^{+}\right)\left(\right.$calcd 498.2440 for $\left.\left[\mathrm{C}_{26} \mathrm{H}_{37} \mathrm{O}_{6} \mathrm{~N} \mathrm{Na}\right]^{+}\right)$.

16, 17-Didehydro-8-desmethyl-isomigrastatin (15): Colorless oil; ${ }^{1} \mathrm{H}$ NMR, see STable $2 ;{ }^{13} \mathrm{C}$ NMR, see STable 3; selected COSY and gHMBC correlations, see SFigure 2; ESI-MS (-), $\mathrm{m} / \mathrm{z}$ $472.2\left([\mathrm{M}-\mathrm{H}]^{+}\right)$; ESI-MS (+), $m / z 473.9\left([\mathrm{M}+\mathrm{H}]^{+}\right), 496.0([\mathrm{M}+\mathrm{Na}])^{+}$.

17-Hydroxy-8-desmethyl-isomigrastatin (16): ESI-MS (-), $m / z$ 490.2 ([M-H $\left.]^{+}\right)$; ESI-MS (+), $m / z$ $492.1\left([\mathrm{M}+\mathrm{H}]^{+}\right)$.

8-Desmethoxy-isomigrastatin (17): Colorless oil; $[\alpha]^{25}{ }_{\mathrm{D}}+77.0^{\circ}\left(c 0.10, \mathrm{CHCl}_{3}\right) ;{ }^{1} \mathrm{H}$ NMR, see STable 2; ${ }^{13} \mathrm{C}$ NMR, see STable 3; selected COSY and gHMBC correlations, see SFigure 2; ESIMS (-), $m / z 458.3[\mathrm{M}-\mathrm{H}]^{+}$; ESI-MS (+), $\mathrm{m} / z$ 460.1 ([M+H] $\left.]^{+}\right), 482.0\left([\mathrm{M}+\mathrm{Na}]^{+}\right)$; HR-MALDIMS $(+), m / z 482.2528\left([\mathrm{M}+\mathrm{Na}]^{+}\right)\left(\right.$calcd 482.2519 for $\left.\left[\mathrm{C}_{26} \mathrm{H}_{37} \mathrm{O}_{6} \mathrm{~N} \mathrm{Na}\right]^{+}\right)$.

16, 17-Didehydro-8-desmethoxy-isomigrastatin (18): Colorless oil; $[\alpha]^{25}+7.3^{\circ}\left(c 0.05, \mathrm{CHCl}_{3}\right)$; ${ }^{1} \mathrm{H}$ NMR, see STable $2 ;{ }^{13} \mathrm{C}$ NMR, see STable 3; selected COSY and gHMBC correlations, see SFigure 2; ESI-MS (-), $m / z 456.2\left([\mathrm{M}-\mathrm{H}]^{+}\right)$; ESI-MS (+), $m / z 458.0\left([\mathrm{M}+\mathrm{H}]^{+}\right), 480.0\left([\mathrm{M}+\mathrm{Na}]^{+}\right)$.

17-Hydroxy-8-desmethoxy-isomigrastatin (19): Colorless oil; $\left.[\alpha]^{25}{ }_{\mathrm{D}}+80.0^{\circ}(c) 0.10, \mathrm{CHCl}_{3}\right) ;{ }^{1} \mathrm{H}$ NMR, see STable 2; ${ }^{13} \mathrm{C}$ NMR, see STable 3; selected COSY and gHMBC correlations, see SFigure 2; ESI-MS (-), $m / z 474.2\left([\mathrm{M}-\mathrm{H}]^{+}\right)$; ESI-MS (+), $m / z 476.0\left([\mathrm{M}+\mathrm{H}]^{+}\right), 498.0\left([\mathrm{M}+\mathrm{Na}]^{+}\right)$.

$\mathrm{H}_{2} \mathrm{O}$-mediated rearrangement of 12-14 and 17-19. A general reaction method is described as follows. Each of the purified 12-15 and 17-19 $(15 \sim 50 \mathrm{mg})$ was dissolved in appropriate volume of $\mathrm{CHCl}_{3}$, transferred into a round flask $(250 \sim 500 \mathrm{~mL})$ and evaporated to dryness. Then warm Milli$\mathrm{Q} \mathrm{H}_{2} \mathrm{O}\left(37^{\circ} \mathrm{C}\right)$ was added to the flask to form an approximate $0.4 \mathrm{mM}$ solution. The mixture was stirred by rotation in water bath at $37^{\circ} \mathrm{C}$ for $2 \mathrm{hr}$ (this led to $>90 \%$ conversion rate) and then at $90 \sim 100{ }^{\circ} \mathrm{C}$ for additional $20 \mathrm{~min}$ to complete the conversion. The resulting mixture was evaporated under reduced pressure to dryness and the residue was subjected to HPLC and LC-ESI-MS 
analyses. All the congeners tested were converted to essentially four products (see SFigure 3 and STable 4).

Purification of the reaction products was achieved by silica gel flash column chromatography, eluted with a $\mathrm{CHCl}_{3} / \mathrm{MeOH}$ (9.8:0.2-8:2, containing 0.1\% HOAc) gradient and subsequently via semi-preparative HPLC. For example, the reaction products of $17(50 \mathrm{mg})$ was loaded on silica gel flash column $(1.3 \times 30 \mathrm{~cm})$ and eluted with a $\mathrm{CHCl}_{3} / \mathrm{MeOH} / \mathrm{HOAc}$ (98:2:0.1-90:10:0.1) gradient to afford purified $24(10 \mathrm{mg}), \mathbf{4 2}(15 \mathrm{mg})$, and a mixture containing 36 and 30 that was further separated by semi-preparative HPLC to yield $\mathbf{3 6}(7 \mathrm{mg})$ and $\mathbf{3 0}(12 \mathrm{mg})$. Similar procedure resulted in the purification of all the compounds listed in STable 4.

The structures of the products in STable 4 were deduced by comparison of their HPLC chromatographic properties with the corresponding rearrangement products of $\mathbf{1 0}$ that have been well established previously, and were further confirmed by ESI-MS data (STable 4). In addition, the structures of all the congeners (20-25) of 1 were further subjected to 1D and 2D NMR (COSY, TOCSY, HMQC and $g$ HMBC) analyses (see SFigure 4 and STable 5-7). Representative dorrigocin congeners 27, 28, 30, 34, 36, 39, 40 and 42 were also confirmed by 1D and 2D NMR (COSY, HMQC and $g \mathrm{HMBC}$ ) analyses (see STable 8-10).

Cysteine 1, 4-Michael addition of 10, 13, 14, 17 and 19: A general reaction approach is described as follows. To a solution of purified 10, 13, 14, 17, or $19(10-30 \mathrm{mg})$ in $\mathrm{MeOH}(\sim 0.5$ $\mathrm{mM})$ at room temperature was slowly added an equal volume of solution of L-cysteine $(1 \mathrm{mM})$ in $\mathrm{H}_{2} \mathrm{O}$. The resultant mixture was stirred at room temperature for $10 \mathrm{~min}$. HPLC analysis revealed that the 1,4-Michael addition reaction was completed in $2 \mathrm{~min}$. The reaction mixture was evaporated in vacuum to dryness. The residue was dissolved in small amount of $\mathrm{MeOH}-\mathrm{H}_{2} \mathrm{O}(1: 1)$, filtrated, and analyzed by HPLC (see SFigure 5 and STable 11). Purification of the diasteromers (at C-3) was achieved by semi-preparative HPLC. While the two diasteromers of 44 and 45 (from 10) or 5 and $\mathbf{6}$ (from 13) were inseparable under the standard HPLC condition described above (i.e. a linear gradient of $15 \% \mathrm{CH}_{3} \mathrm{CN}$ to $80 \% \mathrm{CH}_{3} \mathrm{CN}$ in $\mathrm{H}_{2} \mathrm{O}$ containing $0.1 \%$ HOAc over $20 \mathrm{~min}$ ) described, they were well resolved by an alternative solvent system with a linear gradient of $20 \% \mathrm{MeOH}$ to $80 \% \mathrm{MeOH}$ in $\mathrm{H}_{2} \mathrm{O}$ over 20 min (SFigure 5).

The structures of the cysteine adducts were confirmed by LC-ESI-MS (STable 11). Selected pairs of diasteromers, such as $\mathbf{5 / 6}$ and $\mathbf{4 4 / 4 5}$, were further verified by 1D and 2D NMR (COSY, HMQC and $g$ HMBC) analyses (STables 12-14). The ${ }^{1} \mathrm{H}$ and ${ }^{13} \mathrm{C}$ NMR spectra data of 5 and 6 (all measured in $\mathrm{D}_{2} \mathrm{O}$ ) were in good agreement with those reported for NK30424 A and B, respectively.

\section{Stereochemistry determination.}

Iso-Migrastatin (10) and its congeners (12-19). We have previously demonstrated that 10 undergoes rapid conversion to $\mathbf{1}^{1}$ Since the absolute stereochemistry of $\mathbf{1}$ has been determined by $\mathrm{X}$-ray crystallographic analysis of an $\mathrm{N}$-p-bromophenacylated derivative, ${ }^{2}$ we concluded that $\mathbf{1 0}$ has the same configuration as $\mathbf{1}$ at $\mathrm{C}-8,-9,-10$, and -14 (i.e., $8 S, 9 S, 10 S$, and $14 S$ for 10). ${ }^{1}$ This early work, however, left the stereogenic center at $\mathrm{C}-11$ for $\mathbf{1 0}$ unassigned. ${ }^{1}$ The relative stereochemistry of 10 has recently been established by X-ray crystallographic analysis. ${ }^{3}$ Taken together, these results have now allowed us finally complete the stereochemistry assignment for $\mathbf{1 0}$ with $11 R$ configuration. ${ }^{3}$ Consequently, congeners 12-19 were assigned to have the same configuration at $\mathrm{C}$ $8,-9,-10,-11$, and -14 (if applicable) as $\mathbf{1 0}$ on the basis of their biosynthetic origin (Figure 2), which was further confirmed by comparative analyses of their ${ }^{1} \mathrm{H}$ and ${ }^{13} \mathrm{C}$ NMR splitting patterns and chemical shifts. The C-16/C-17 trans double bond (for 12, 15, and 18) was based on its diagnostic coupling constant $(J=16 \mathrm{~Hz})$. The HO- group at $\mathrm{C}-17$ (for 13 and 19) was assigned $R$ configuration on the basis of its near identical splitting patterns and chemical shifts at $\mathrm{C}-15,-16$, $17,-18$, and -19 to those of streptimidone $(\mathbf{8})$ (all measured in $\mathrm{CDCl}_{3}$ ), the absolute $R$ configuration of which had been determined and the high resolution NMR data of which had been reported previously. ${ }^{4}$ The identical stereocenters at C-8, $-9,-10$, and -11 for 10 and its congeners (12-19) 
were consistent with the ${ }^{1} \mathrm{H}^{1}{ }^{1} \mathrm{H}$ coupling constants $\left[J_{\mathrm{H} 7, \mathrm{H} 8 \alpha}=4.0 \mathrm{~Hz}, J_{\mathrm{H} 8 \alpha, \mathrm{H} 9 \beta_{1}}=9.0-9.5 \mathrm{~Hz}, J_{\mathrm{H} 9 \beta_{, \mathrm{H} 8 \beta}}=\right.$ $3.5-4.0 \mathrm{~Hz}$ (if applicable), $J_{\mathrm{H} 9 \beta, \mathrm{H} 10 \beta}=0 \mathrm{~Hz}$, and $\left.J_{\mathrm{H} 11 \alpha, \mathrm{H} 10 \beta}=3.5-4.0 \mathrm{~Hz}\right]$ and ${ }^{13} \mathrm{C} \mathrm{NMR}$ chemical shifts as summarized in STables 1-3.

Migrastatin (1) and its congeners (20-25). The absolute stereochemistry of $\mathbf{1}$ has been determined previously by X-ray crystallographic analysis. ${ }^{2}$ The absolute stereochemistry of $\mathbf{1 0}$ has been completely assigned in this work (see above). The stereochemistry relationship for $\mathbf{1 0}$ to undergo the $\mathrm{H}_{2} \mathrm{O}$-mediated rearrangement to $\mathbf{1}$ has been established previously. ${ }^{1}$ The same stereochemistry relationship between $\mathbf{1 0}$ and $\mathbf{1}$ was applied here to the stereochemistry assignments for congeners 20-25 according to their corresponding substrates 12, 13, 14, 19, 17, and 18, respectively. These assignments are in perfect agreement with their ${ }^{1} \mathrm{H}$ and ${ }^{13} \mathrm{C}$ NMR data upon comparison with those of $\mathbf{1}$ as summarized in STables 5-7.

Dorrigocin A (2) and 13-epi-dorrigocin A (11) and their congeners (26-37). The absolute stereochemistry of $\mathbf{2}$ and $\mathbf{1 1}$ has been determined, and the stereochemistry relationship for $\mathbf{1 0}$ to undergo the $\mathrm{H}_{2} \mathrm{O}$-mediated rearrangement to $\mathbf{2}$ and $\mathbf{1 1}$ has been established previously. ${ }^{\mathrm{S} 1}$ The same stereochemistry relationship between $\mathbf{1 0}$ and its resultant products $\mathbf{2}$ and $\mathbf{1 1}$ was applied here to the stereochemistry assignments for congeners 26-37 according to their corresponding substrates $\mathbf{1 2}$, 13, 14, 19, 17, and 18, respectively. The chemical shifts of $\mathrm{H}-13$ for 2 and its congeners resonate at $\sim 4.00 \mathrm{ppm}(J=10.0 \mathrm{~Hz})$, while those of $\mathrm{H}-13$ for $\mathbf{1 1}$ and its congeners shift downfiled to 4.15 $\operatorname{ppm}(J=7.0 \mathrm{~Hz})$. These assignments are in perfect agreement with selected ${ }^{1} \mathrm{H}$ and ${ }^{13} \mathrm{C}$ NMR data upon comparison with 2 and 11, respectively, as summarized in STables 8-10.

Dorrigocin B (3) and its congeners (38-43). We have previously assigned the stereochemistry for 3 as $8 S, 9 S, 10 S$, and $14 S$ with the configuration at C-11 unassigned. ${ }^{1}$ Similar to those described for the complete stereochemistry assignment for 10 and its congeners 12-19, we can now complete the stereochemistry assignment for $\mathbf{3}$ with $11 R$ configuration. ${ }^{3}$ The same stereochemistry relationship between $\mathbf{1 0}$ and $\mathbf{2}$ was applied here to the stereochemistry assignments for congeners 38-43 according to their corresponding substrates 12, 13, 14, 19, 17, and 18, respectively. These assignments are in perfect agreement with selected ${ }^{1} \mathrm{H}$ and ${ }^{13} \mathrm{C}$ NMR data upon comparison with $\mathbf{3}$ as summarized in STables 9 and 10.

NK30424 A (5) and B (6) and their congeners (44-51). First isolated from Streptomyces sp. NA30424, 5 and $\mathbf{6}$ were established as two stereoisomers at C-3, with their relative and absolute stereochemistry undetermined. ${ }^{5}$ Viewing $\mathbf{5}$ and $\mathbf{6}$ as a cysteine 1,4-adduct at C-2/C-3 of 13, we incubated 13 with cysteine. It indeed afforded in quantitative yield two diastereomers at C-3 in an approximately 2:3 ratio (SFigure 5), whose identity as $\mathbf{5}$ and $\mathbf{6}$ was confirmed by their identical ${ }^{1} \mathrm{H}$ and ${ }^{13} \mathrm{C}$ NMR data to those reported previously (STables 13 and 14). ${ }^{5}$ Since we have established the absolute stereochemistry of $\mathbf{1 3}$ (see above), the quantitative conversion of $\mathbf{1 3}$ to $\mathbf{5}$ and $\mathbf{6}$ upon cysteine addition allowed us to conclude that $\mathbf{5}$ and $\mathbf{6}$ have the same configuration as $\mathbf{1 3}$ at C-8, -9, $10,-11,-14$, and -17 (i.e., $8 S, 9 S, 10 S, 11 R, 14 S$, and 17R). The same stereochemistry relationship between 13 and its resultant adducts 5 and $\mathbf{6}$ was applied here to the stereochemistry assignments for congeners 44-51 according to their corresponding substrates 10, 14, 17, and 19, respectively. These assignments are in perfect agreement with selected ${ }^{1} \mathrm{H}$ and ${ }^{13} \mathrm{C}$ NMR data as summarized in STables 12-14. Attempt to differentiate the two diastereomers at $\mathrm{C}-3$ by NMR analysis was inconclusive, however, and the stereochemistry at C-3 for 5, 6 and their congeners 44-51, therefore, remained unassigned. 
STable 1. ${ }^{1} \mathrm{H}$ NMR (500 MHz) spectral data of $\mathbf{1 0}$ and $\mathbf{1 2 - 1 4}{ }^{a}$ in $\mathrm{CDCl}_{3}$

\begin{tabular}{|c|c|c|c|c|}
\hline Position & 10 & 12 & 13 & 14 \\
\hline 2 & $5.69,1 \mathrm{H}, \mathrm{d}(16.0)$ & $5.69,1 \mathrm{H}, \mathrm{d}(15.5)$ & $5.70,1 \mathrm{H}, \mathrm{d}(16.0)$ & $5.70,1 \mathrm{H}, \mathrm{d}(15.5)$ \\
\hline 3 & $6.65,1 \mathrm{H}$, ddd $(16.0,8.5,7.5)$ & $6.64,1 \mathrm{H}$, ddd $(15.5,8.5,7.5)$ & $6.66,1 \mathrm{H}, \mathrm{ddd}(16.0,9.0,7.0)$ & $6.65,1 \mathrm{H}, \mathrm{ddd}(15.5,9.5,7.5)$ \\
\hline \multirow[t]{2}{*}{4} & $2.15,1 \mathrm{H}, \mathrm{m}$ & $2.16,1 \mathrm{H}, \mathrm{m}$ & $2.18,1 \mathrm{H}, \mathrm{m}$ & $2.15,1 \mathrm{H}, \mathrm{m}$ \\
\hline & $2.45,1 \mathrm{H}, \mathrm{m}$ & $2.45,1 \mathrm{H}, \mathrm{m}$ & $2.42,1 \mathrm{H}, \mathrm{m}$ & $2.43,1 \mathrm{H}, \mathrm{m}$ \\
\hline \multirow[t]{2}{*}{5} & $1.96,1 \mathrm{H}, \mathrm{m}$ & $1.96,1 \mathrm{H}, \mathrm{m}$ & $1.95,1 \mathrm{H}, \mathrm{m}$ & $1.95,1 \mathrm{H}, \mathrm{m}$ \\
\hline & $2.60,1 \mathrm{H}, \mathrm{m}$ & $2.63,1 \mathrm{H}, \mathrm{m}$ & $2.62,1 \mathrm{H}, \mathrm{m}$ & $2.60,1 \mathrm{H}, \mathrm{m}$ \\
\hline 6 & $5.60,1 \mathrm{H}, \mathrm{ddd}(15.5,11.0,4.5)$ & $5.61,1 \mathrm{H}, \operatorname{ddd}(15.5,11.0,4.0)$ & $5.61,1 \mathrm{H}, \operatorname{ddd}(15.5,10.0,4.0)$ & $5.75,1 \mathrm{H}, \mathrm{ddd}(15.5,9.5,3.5)$ \\
\hline 7 & $5.10,1 \mathrm{H}, \mathrm{dd}(15.5,3.5)$ & $5.10,1 \mathrm{H}, \mathrm{dd}(15.5,3.5)$ & $5.10,1 \mathrm{H}, \mathrm{dd}(15.5,3.6)$ & $5.29,1 \mathrm{H}, \mathrm{dd}(15.5,4.0)$ \\
\hline 8 & $3.43,1 \mathrm{H}$, (overlap) & $3.43,1 \mathrm{H}, \mathrm{m}$ & $3.46,1 \mathrm{H}$, (overlap) & $3.96,1 \mathrm{H}, \mathrm{dd}(9.5,4.0)$ \\
\hline 9 & $3.75,1 \mathrm{H}, \mathrm{d}(9.5)$ & $3.77,1 \mathrm{H}, \mathrm{d}(9.0)$ & $3.76,1 \mathrm{H}, \mathrm{d}(9.0)$ & $3.94,1 \mathrm{H}, \mathrm{d}(9.0)$ \\
\hline 10 & $1.85,1 \mathrm{H}, \mathrm{m}$ & $1.85,1 \mathrm{H}, \mathrm{m}$ & $1.86,1 \mathrm{H}, \mathrm{m}$ & $1.88,1 \mathrm{H}, \mathrm{m}$ \\
\hline 11 & $5.20,1 \mathrm{H}$, (overlap) & $5.22,1 \mathrm{H}$, (overlap) & $5.22,1 \mathrm{H}, \mathrm{d}(4.0)$ & $5.21,1 \mathrm{H}, \mathrm{d}(4.0)$ \\
\hline 13 & $5.20,1 \mathrm{H}$, (overlap) & $5.22,1 \mathrm{H}$, (overlap) & $5.17,1 \mathrm{H}$, br.d $(9.5)$ & $5.24,1 \mathrm{H}$, br.d $(10.0)$ \\
\hline 14 & $3.43,1 \mathrm{H}, \mathrm{m}$ & $3.60,1 \mathrm{H}, \mathrm{m}$ & $3.46,1 \mathrm{H}$, (overlap) & $3.46,1 \mathrm{H}, \mathrm{m}$ \\
\hline \multirow[t]{2}{*}{16} & $2.39,1 \mathrm{H}, \mathrm{m}$ & $6.32,1 \mathrm{H}, \mathrm{d}(16.0)$ & $2.55,1 \mathrm{H}, \mathrm{dd}(18.0,3.5)$ & $2.40,1 \mathrm{H}, \mathrm{m}$ \\
\hline & $2.62,1 \mathrm{H}, \mathrm{m}$ & & $2.75,1 \mathrm{H}, \mathrm{m}$ & $2.62,1 \mathrm{H}, \mathrm{m}$ \\
\hline 17 & $1.59,2 \mathrm{H}, \mathrm{m}$ & $6.76,1 \mathrm{H}, \mathrm{dt}(16.0,7.0)$ & $4.08,1 \mathrm{H}, \mathrm{m}$ & $1.59,2 \mathrm{H}, \mathrm{m}$ \\
\hline \multirow[t]{2}{*}{18} & $1.36,2 \mathrm{H}, \mathrm{m}$ & $2.32,2 \mathrm{H}, \mathrm{m}$ & $1.58,1 \mathrm{H}, \mathrm{ddd}(14.0,10.0,5.0)$ & $1.38,2 \mathrm{H}, \mathrm{m}$ \\
\hline & & & $1.40,1 \mathrm{H}$, ddd $(14.0,9.0,3.0)$ & \\
\hline 19 & $2.10,1 \mathrm{H}, \mathrm{m}$ & $2.34,1 \mathrm{H}, \mathrm{m}$ & $2.46,1 \mathrm{H}, \mathrm{m}$ & $2.13,1 \mathrm{H}, \mathrm{m}$ \\
\hline \multirow[t]{2}{*}{20} & $2.25,1 \mathrm{H}, \mathrm{m}$ & $2.28,1 \mathrm{H}, \mathrm{m}$ & $2.32,1 \mathrm{H}, \mathrm{m}$ & $2.22,1 \mathrm{H}, \mathrm{m}$ \\
\hline & $2.70,1 \mathrm{H}, \mathrm{m}$ & $2.73,1 \mathrm{H}, \mathrm{m}$ & $2.80,1 \mathrm{H}, \mathrm{m}$ & $2.68,1 \mathrm{H}, \mathrm{m}$ \\
\hline 22 & $0.87,3 \mathrm{H}, \mathrm{d}(7.5)$ & $0.83, \mathrm{~d}(7.0)$ & $0.87,3 \mathrm{H}, \mathrm{d}(7.5)$ & $0.88,3 \mathrm{H}, \mathrm{d}(7.0)$ \\
\hline 23 & $1.90,3 \mathrm{H}, \mathrm{d}(1.5)$ & $1.94,3 \mathrm{H}, \mathrm{d}(1.0)$ & $1.90,3 \mathrm{H}, \mathrm{d}(1.5)$ & $1.89,3 \mathrm{H}, \mathrm{d}(1.5)$ \\
\hline 24 & $1.14,3 \mathrm{H}, \mathrm{d}(7.0)$ & $1.18,3 \mathrm{H}, \mathrm{d}(6.5)$ & $1.16,3 \mathrm{H}, \mathrm{d}(7.0)$ & $1.18,3 \mathrm{H}, \mathrm{d}(7.0)$ \\
\hline \multirow[t]{2}{*}{25} & $2.25,1 \mathrm{H}, \mathrm{m}$ & $2.28,1 \mathrm{H}, \mathrm{m}$ & $2.32,1 \mathrm{H}, \mathrm{m}$ & $2.22,1 \mathrm{H}, \mathrm{m}$ \\
\hline & $2.70,1 \mathrm{H}, \mathrm{m}$ & $2.73,1 \mathrm{H}, \mathrm{m}$ & $2.75,1 \mathrm{H}, \mathrm{m}$ & $2.68,1 \mathrm{H}, \mathrm{m}$ \\
\hline $8-\mathrm{OCH} 3$ & $3.34,3 \mathrm{H}, \mathrm{s}$ & $3.34,3 \mathrm{H}, \mathrm{s}$ & $3.34,3 \mathrm{H}, \mathrm{s}$ & \\
\hline $\mathrm{NH}$ & & $7.80,1 \mathrm{H}$, br.s & $7.86,1 \mathrm{H}$, br.s & $8.35,1 \mathrm{H}$, br.s \\
\hline
\end{tabular}

${ }^{a}$ Signals were assigned with aid of ${ }^{1} \mathrm{H}-{ }^{1} \mathrm{H}$ COSY, TOCSY, HMQC, and gHMBC experiments. 
STable 2. ${ }^{1} \mathrm{H}$ NMR $(500 \mathrm{MHz})$ spectral data of $\mathbf{1 5}^{a}$ and $\mathbf{1 7 - 1 9 ^ { a }}$ in $\mathrm{CDCl}_{3}$

\begin{tabular}{|c|c|c|c|c|}
\hline Position & 15 & 17 & 18 & 19 \\
\hline 2 & $5.71,1 \mathrm{H}, \mathrm{d}(15.5)$ & $5.67,1 \mathrm{H}, \mathrm{d}(16.0)$ & $5.70,1 \mathrm{H}, \mathrm{d}(16.0)$ & $5.65,1 \mathrm{H}, \mathrm{d}(15.5)$ \\
\hline 3 & $6.64,1 \mathrm{H}$, overlap & $6.62,1 \mathrm{H}$, ddd $(16.0,9.5,7.5)$ & $6.64,1 \mathrm{H}, \mathrm{ddd}(16.0,8.0,8.0)$ & $6.61,1 \mathrm{H}$, ddd $(15.5,9.5,7.5)$ \\
\hline \multirow[t]{2}{*}{4} & $2.16,1 \mathrm{H}, \mathrm{m}$ & $2.14,1 \mathrm{H}, \mathrm{m}$ & $2.12,1 \mathrm{H}, \mathrm{m}$ & $2.15,1 \mathrm{H}, \mathrm{m}$ \\
\hline & $2.42,1 \mathrm{H}, \mathrm{m}$ & $2.42,1 \mathrm{H}, \mathrm{m}$ & $2.42,1 \mathrm{H}, \mathrm{m}$ & $2.42,1 \mathrm{H}, \mathrm{m}$ \\
\hline \multirow[t]{2}{*}{5} & $1.94,1 \mathrm{H}, \mathrm{m}$ & $1.88,1 \mathrm{H}, \mathrm{m}$ & $1.88,1 \mathrm{H}, \mathrm{m}$ & $1.90,1 \mathrm{H}, \mathrm{m}$ \\
\hline & $2.60,1 \mathrm{H}, \mathrm{m}$ & $2.52,1 \mathrm{H}, \mathrm{m}$ & $2.52,1 \mathrm{H}, \mathrm{m}$ & $2.55,1 \mathrm{H}, \mathrm{m}$ \\
\hline 6 & $5.76,1 \mathrm{H}$, (overlap) & $5.33,1 \mathrm{H}$, (overlap) & $5.36,1 \mathrm{H}, \operatorname{ddd}(15.5,10.5,4.0)$ & $5.32,1 \mathrm{H}, \mathrm{ddd}(15.5,10.5,5.0)$ \\
\hline 7 & $5.28,1 \mathrm{H}$, (overlap) & $5.02,1 \mathrm{H}, \mathrm{ddd}(15.5,9.5,6.0)$ & $5.04,1 \mathrm{H}$, ddd $(15.5,7.0,6.5)$ & $5.00,1 \mathrm{H}$, ddd $(15.5,9.5,6.0)$ \\
\hline \multirow[t]{2}{*}{8} & $3.97,1 \mathrm{H}, \mathrm{dd}(9.0,4.0)$ & $2.10,1 \mathrm{H}, \mathrm{m}$ & $2.08,1 \mathrm{H}, \mathrm{m}$ & $2.15,1 \mathrm{H}, \mathrm{m}$ \\
\hline & & $2.21,1 \mathrm{H}, \mathrm{m}$ & $2.22,1 \mathrm{H}, \mathrm{m}$ & $2.21,1 \mathrm{H}, \mathrm{m}$ \\
\hline 9 & $3.77,1 \mathrm{H}, \mathrm{d}(9.5)$ & $4.01,1 \mathrm{H}, \mathrm{dd}(11.0,4.0)$ & $4.02,1 \mathrm{H}, \mathrm{dd}(11.0,3.5)$ & $3.97,1 \mathrm{H}, \mathrm{dd}(11.0,4.0)$ \\
\hline 10 & $1.90,1 \mathrm{H}, \mathrm{m}$ & $1.91,1 \mathrm{H}, \mathrm{m}$ & $1.92,1 \mathrm{H}, \mathrm{m}$ & $1.89,1 \mathrm{H}, \mathrm{m}$ \\
\hline 11 & $5.24,1 \mathrm{H}$, (overlap) & $5.22,1 \mathrm{H}, \mathrm{d}(3.5)$ & $5.24,1 \mathrm{H}, \mathrm{d}(4.0)$ & $5.20,1 \mathrm{H}$, (overlap) \\
\hline 13 & $5.25,1 \mathrm{H}$, (overlap) & $5.34,1 \mathrm{H}$, (overlap) & $5.32,1 \mathrm{H}, \mathrm{d}(9.5)$ & $5.20,1 \mathrm{H}$, (overlap) \\
\hline 14 & $3.60,1 \mathrm{H}, \mathrm{m}$ & $3.43,1 \mathrm{H}, \mathrm{m}$ & $3.60,1 \mathrm{H}, \mathrm{m}$ & $3.42,1 \mathrm{H}, \mathrm{m}$ \\
\hline \multirow[t]{2}{*}{16} & $6.31,1 \mathrm{H}, \mathrm{d}(15.5)$ & $2.44,1 \mathrm{H}, \mathrm{m}$ & $6.26,1 \mathrm{H}, \mathrm{d}(15.0)$ & $2.50,1 \mathrm{H}, \mathrm{m}$ \\
\hline & & $2.54,1 \mathrm{H}, \mathrm{m}$ & & $2.70,1 \mathrm{H}, \mathrm{m}$ \\
\hline 17 & $6.79,1 \mathrm{H}, \mathrm{dt}(15.5,7.0)$ & $1.60,2 \mathrm{H}, \mathrm{m}$ & $6.78,1 \mathrm{H}, \mathrm{dt}(15.0,6.5)$ & $4.09,1 \mathrm{H}, \mathrm{tt}(9.5,3.0)$ \\
\hline \multirow[t]{2}{*}{18} & $2.30,2 \mathrm{H}, \mathrm{m}$ & $1.34,2 \mathrm{H}, \mathrm{m}$ & $2.30,2 \mathrm{H}, \mathrm{m}$ & $1.55,1 \mathrm{H}$, ddd $(14.0,10.5,5.5)$ \\
\hline & & & & $1.32,1 \mathrm{H}, \mathrm{ddd}(14.0,8.5,3.0)$ \\
\hline 19 & $2.34,1 \mathrm{H}, \mathrm{m}$ & $1.90,1 \mathrm{H}, \mathrm{m}$ & $2.32,1 \mathrm{H}, \mathrm{m}$ & $2.45,1 \mathrm{H}, \mathrm{m}$ \\
\hline \multirow[t]{2}{*}{20} & $2.32,1 \mathrm{H}, \mathrm{m}$ & $2.26,1 \mathrm{H}, \mathrm{m}$ & $2.32,1 \mathrm{H}, \mathrm{m}$ & $2.31,1 \mathrm{H}, \mathrm{m}$ \\
\hline & $2.76,1 \mathrm{H}, \mathrm{m}$ & $2.69,1 \mathrm{H}, \mathrm{dd}(17.0,4.0)$ & $2.72,1 \mathrm{H}, \mathrm{m}$ & $2.76,1 \mathrm{H}, \mathrm{m}$ \\
\hline 22 & $0.86,3 \mathrm{H}, \mathrm{d}(7.0)$ & $0.88,3 \mathrm{H}, \mathrm{d}(7.5)$ & $0.87, \mathrm{~d}(6.5)$ & $0.83,3 \mathrm{H}, \mathrm{d}(7.5)$ \\
\hline 23 & $1.92,3 \mathrm{H}, \mathrm{d}(1.0)$ & $1.85,3 \mathrm{H}, \mathrm{d}(1.5)$ & $1.91,3 \mathrm{H}$, br.s & $1.85,3 \mathrm{H}, \mathrm{d}(1.0)$ \\
\hline 24 & $1.20,3 \mathrm{H}, \mathrm{d}(7.0)$ & $1.17,3 \mathrm{H}, \mathrm{d}(7.0)$ & $1.22,3 \mathrm{H}, \mathrm{d}(7.0)$ & $1.16,3 \mathrm{H}, \mathrm{d}(7.0)$ \\
\hline \multirow[t]{2}{*}{25} & $2.30,1 \mathrm{H}, \mathrm{m}$ & $2.26,1 \mathrm{H}, \mathrm{m}$ & $2.32,1 \mathrm{H}, \mathrm{m}$ & $2.31,1 \mathrm{H}, \mathrm{m}$ \\
\hline & $2.76,1 \mathrm{H}, \mathrm{m}$ & $2.69,1 \mathrm{H}, \mathrm{dd}(17.0,4.0)$ & $2.72,1 \mathrm{H}, \mathrm{m}$ & $2.78,1 \mathrm{H}, \mathrm{m}$ \\
\hline $\mathrm{NH}$ & $7.80,1 \mathrm{H}$, br.s & $8.39,1 \mathrm{H}$, br.s & $7.86,1 \mathrm{H}$, br.s & $7.95,1 \mathrm{H}$, br.s \\
\hline
\end{tabular}

${ }^{a}$ Signals were assigned with aid of ${ }^{1} \mathrm{H}-{ }^{1} \mathrm{H}$ COSY, TOCSY, HMQC, and gHMBC experiments. 
STable 3. ${ }^{13} \mathrm{C}$ NMR (125 MHz) spectral data of $\mathbf{1 0}$ and $\mathbf{1 2 - 1 9}{ }^{a}$ in $\mathrm{CDCl}_{3}$

\begin{tabular}{|c|c|c|c|c|c|c|c|c|}
\hline Position & 10 & 12 & 13 & 14 & 15 & 17 & 18 & 19 \\
\hline 1 & 167.8 & 167.0 & 167.8 & 167.7 & 167.8 & 167.8 & 168.0 & 167.9 \\
\hline 2 & 125.2 & 125.3 & 125.1 & 125.2 & 125.2 & 125.1 & 125.3 & 125.1 \\
\hline 3 & 150.8 & 150.6 & 151.0 & 151.0 & 151.0 & 150.9 & 150.8 & 151.0 \\
\hline 4 & $30.3 *$ & 30.3 & 30.3 & 30.4 & 30.4 & 30.6 & 30.6 & 30.6 \\
\hline 5 & 32.9 & 32.9 & 33.0 & 32.8 & 32.8 & 32.9 & 33.0 & 33.0 \\
\hline 6 & 129.3 & 129.3 & 129.5 & 128.3 & 128.3 & 131.4 & 131.2 & 130.7 \\
\hline 7 & 130.5 & 130.6 & 130.4 & 134.5 & 134.8 & 130.8 & 130.9 & 131.5 \\
\hline 8 & 81.8 & 81.9 & 81.7 & 71.7 & 71.8 & 38.0 & 38.2 & 38.2 \\
\hline 9 & 73.4 & 73.4 & 73.7 & 74.6 & 74.8 & 71.4 & 71.5 & 71.7 \\
\hline 10 & 38.3 & 38.3 & 38.4 & 38.6 & 38.7 & 39.7 & 39.7 & 39.8 \\
\hline 11 & 82.4 & 82.5 & 82.2 & 81.7 & 81.9 & 81.5 & 81.9 & 81.5 \\
\hline 12 & 134.3 & 134.5 & 135.3 & 134.2 & 134.3 & 134.9 & 135.1 & 135.8 \\
\hline 13 & 128.2 & 127.9 & 127.3 & 127.9 & 127.8 & 127.4 & 127.5 & 126.6 \\
\hline 14 & 46.2 & 44.8 & 46.8 & 46.1 & 44.9 & 46.0 & 44.8 & 46.6 \\
\hline 15 & 211.0 & 199.7 & 212.3 & 210.9 & 199.6 & 210.9 & 199.6 & 212.2 \\
\hline 16 & 40.1 & 131.6 & 47.5 & 40.2 & 131.3 & 40.2 & 131.4 & 47.6 \\
\hline 17 & 20.5 & 141.2 & 65.3 & 20.4 & 141.8 & 20.5 & 141.8 & 65.0 \\
\hline 18 & 34.4 & 37.7 & 41.2 & 34.2 & $37.6^{*}$ & 34.2 & 37.5 & 40.8 \\
\hline 19 & $30.3 *$ & 29.8 & 27.3 & 30.2 & 29.7 & 30.4 & 29.6 & 27.2 \\
\hline 20 & 37.9 & 37.5 & 38.7 & 38.0 & $37.5^{*}$ & $37.8 *$ & 37.4 & 38.6 \\
\hline 21 & 172.3 & 171.6 & 172.3 & $172.4 *$ & $171.7 *$ & $172.6 *$ & 171.7 & 172.4 \\
\hline 22 & 10.7 & 10.7 & 10.8 & 10.7 & 10.8 & 9.4 & 9.5 & 9.4 \\
\hline 23 & 13.5 & 13.3 & 13.7 & 14.2 & 14.0 & 14.6 & 14.2 & 14.5 \\
\hline 24 & 15.9 & 15.5 & 15.7 & 16.2 & 16.0 & 16.4 & 16.2 & 15.9 \\
\hline 25 & 37.9 & 37.5 & 37.5 & 37.9 & $37.4 *$ & $37.8 *$ & 37.3 & 37.4 \\
\hline 26 & 172.3 & 171.6 & 172.2 & $172.4 *$ & $171.7 *$ & $172.6 *$ & 171.7 & 172.4 \\
\hline 8-OCH3 & 57.3 & 57.3 & 57.3 & & & & & \\
\hline
\end{tabular}

${ }^{a}$ Signals were assigned with aid of ${ }^{1} \mathrm{H}^{1}{ }^{1} \mathrm{H}$ COSY, TOCSY, HMQC, and gHMBC experiments. *Overlapped signals or signals that could be interchangeable. 
STable 4. Dorrigocin (26-43) and migrastatin (20-25) analogs resulted from $\mathrm{H}_{2} \mathrm{O}$-mediated rearrangement of 12-14 and 17-19 and their LC-ESI-MS data (acquired in both positive and negative mode)

\begin{tabular}{|c|c|c|c|c|}
\hline Substrates & \multicolumn{4}{|c|}{ Products } \\
\hline & 13-epi-dorrigocin A series & dorrigocin B-series & Dorrigocin A series & Migrastatin-series \\
\hline 12 & $\begin{array}{c}3 \mathbf{3 2} \\
m / z .527 .9\left([\mathrm{M}+\mathrm{Na}]^{+}\right) \\
m / z .504 .1([\mathrm{M}-\mathrm{H}])^{-}\end{array}$ & $\begin{array}{c}\mathbf{3 8} \\
m / z, 527.9\left([\mathrm{M}+\mathrm{Na}]^{+}\right) ; \\
m / z .504 .1([\mathrm{M}-\mathrm{H}])^{-}\end{array}$ & $\begin{array}{c}\mathbf{2 6} \\
m / z 527.9\left([\mathrm{M}+\mathrm{Na}]^{+}\right) \\
m / z 504.1([\mathrm{M}-\mathrm{H}])^{-}\end{array}$ & $\begin{array}{c}\mathbf{2 0} \\
m / z 510.0\left([\mathrm{M}+\mathrm{Na}]^{+}\right) ; \\
m / z 486.1([\mathrm{M}-\mathrm{H}])^{-}\end{array}$ \\
\hline 13 & $\begin{array}{c}33 \\
m / z 545.9\left([\mathrm{M}+\mathrm{Na}]^{+}\right) \\
m / z 522.2([\mathrm{M}-\mathrm{H}])^{-}\end{array}$ & $\begin{array}{c}39 \\
m / z, 546.0\left([\mathrm{M}+\mathrm{Na}]^{+}\right) ; \\
m / z 522.2([\mathrm{M}-\mathrm{H}])^{-}\end{array}$ & $\begin{array}{c}27 \\
m / z 545.9\left([\mathrm{M}+\mathrm{Na}]^{+}\right) \\
m / z 522.2([\mathrm{M}-\mathrm{H}])^{-}\end{array}$ & $\begin{array}{c}\mathbf{2 1} \\
m / z 527.9\left([\mathrm{M}+\mathrm{Na}]^{+}\right) ; \\
m / z .504 .2([\mathrm{M}-\mathrm{H}])^{-}\end{array}$ \\
\hline 14 & $\begin{array}{c}\mathbf{3 4} \\
m / z 515.9\left([\mathrm{M}+\mathrm{Na}]^{+}\right) \\
m / z 492.2([\mathrm{M}-\mathrm{H}])^{-}\end{array}$ & $\begin{array}{c}4 \mathbf{0} \\
m / z \quad 515.9\left([\mathrm{M}+\mathrm{Na}]^{+}\right) \\
m / z \quad 492.2([\mathrm{M}-\mathrm{H}])^{-}\end{array}$ & $\begin{array}{c}\mathbf{2 8} \\
m / z 515.9\left([\mathrm{M}+\mathrm{Na}]^{+}\right) \\
m / z 492.2([\mathrm{M}-\mathrm{H}])^{-}\end{array}$ & $\begin{array}{c}22 \\
m / z 476.0([\mathrm{M}+\mathrm{H}])^{+} ; \\
m / z 474.2([\mathrm{M}-\mathrm{H}])^{-}\end{array}$ \\
\hline 17 & $\begin{array}{c}3 \mathbf{6} \\
m / z 500.0\left([\mathrm{M}+\mathrm{Na}]^{+}\right) \\
m / z 476.3([\mathrm{M}-\mathrm{H}])^{-}\end{array}$ & $\begin{array}{c}42 \\
m / z, 500.0\left([\mathrm{M}+\mathrm{Na}]^{+}\right) ; \\
m / z 476.3([\mathrm{M}-\mathrm{H}])^{-}\end{array}$ & $\begin{array}{c}3 \mathbf{3 ~ 0} \\
m / z 500.0\left([\mathrm{M}+\mathrm{Na}]^{+}\right) \\
m / z 476.3([\mathrm{M}-\mathrm{H}])^{-}\end{array}$ & $\begin{array}{c}\mathbf{2 4} \\
m / z 460.2([\mathrm{M}+\mathrm{H}])^{+} \\
m / z 458.3([\mathrm{M}-\mathrm{H}])^{-}\end{array}$ \\
\hline 18 & $\begin{array}{c}37 \\
m / z \quad 474.4([\mathrm{M}-\mathrm{H}])^{-}\end{array}$ & $\begin{array}{c}\mathbf{4 3} \\
m / z 474.2([\mathrm{M}-\mathrm{H}])\end{array}$ & $\begin{array}{c}3 \mathbf{1} \\
m / z \quad 474.2([\mathrm{M}-\mathrm{H}])^{-}\end{array}$ & $\begin{array}{c}\mathbf{2 5} \\
m / z \quad 456.2([\mathrm{M}-\mathrm{H}])^{-}\end{array}$ \\
\hline 19 & $\begin{array}{c}\mathbf{3 5} \\
m / z, 515.9([\mathrm{M}+\mathrm{H}])^{+} ; \\
m / z, 492.2([\mathrm{M}-\mathrm{H}])^{-}\end{array}$ & $\begin{array}{c}41 \\
m / z \quad 516.0([\mathrm{M}+\mathrm{H}])^{+} ; \\
m / z 492.2([\mathrm{M}-\mathrm{H}])^{-}\end{array}$ & $\begin{array}{c}29 \\
m / z 516.0([\mathrm{M}+\mathrm{H}])^{+} ; \\
m / z 492.2([\mathrm{M}-\mathrm{H}])^{-}\end{array}$ & $\begin{array}{c}\mathbf{2} 3 \\
m / z 474.2([\mathrm{M}-\mathrm{H}])^{-}\end{array}$ \\
\hline
\end{tabular}


STable 5. ${ }^{1} \mathrm{H}$ NMR (500 MHz) spectral data of $\mathbf{1}$ and $\mathbf{2 0 - 2 2}{ }^{a}$ in $\mathrm{CDCl}_{3}$

\begin{tabular}{|c|c|c|c|c|}
\hline Position & 1 & 20 & 21 & 22 \\
\hline 2 & $5.55,1 \mathrm{H}, \mathrm{dd}(16.0,1.5)$ & $5.59,1 \mathrm{H}, \mathrm{d}(16.0)$ & $5.59,1 \mathrm{H}, \mathrm{d}(15.5)$ & $5.56,1 \mathrm{H}, \mathrm{dd}(16.0,1.5)$ \\
\hline 3 & $6.47,1 \mathrm{H}, \mathrm{ddd}(16.0,10.0,3.5)$ & $6.50,1 \mathrm{H}, \mathrm{ddd}(16.0,10.0,3.5)$ & $6.51,1 \mathrm{H}, \mathrm{ddd}(15.5,10.5,4.0)$ & $6.47,1 \mathrm{H}, \mathrm{ddd}(16.0,10.0,3.0)$ \\
\hline \multirow[t]{2}{*}{4} & $2.20,1 \mathrm{H}, \mathrm{m}$ & $2.14,1 \mathrm{H}, \mathrm{m}$ & $2.22,1 \mathrm{H}, \mathrm{m}$ & $2.17,1 \mathrm{H}, \mathrm{m}$ \\
\hline & $2.41,1 \mathrm{H}, \mathrm{m}$ & $2.42,1 \mathrm{H}, \mathrm{m}$ & $2.44,1 \mathrm{H}, \mathrm{m}$ & $2.44,1 \mathrm{H}, \mathrm{m}$ \\
\hline \multirow[t]{2}{*}{5} & $2.20,1 \mathrm{H}, \mathrm{m}$ & $2.181 \mathrm{H}, \mathrm{m}$ & $2.24,1 \mathrm{H}, \mathrm{m}$ & $2.17,1 \mathrm{H}, \mathrm{m}$ \\
\hline & $2.41,1 \mathrm{H}, \mathrm{m}$ & $2.42,1 \mathrm{H}, \mathrm{m}$ & $2.42,1 \mathrm{H}, \mathrm{m}$ & $2.44,1 \mathrm{H}, \mathrm{m}$ \\
\hline 6 & $5.50,1 \mathrm{H}, \operatorname{ddd}(15.5,10.0,5.0)$ & $5.53,1 \mathrm{H}, \operatorname{ddd}(15.5,9.0,5.0)$ & $5.54,1 \mathrm{H}, \mathrm{ddd}(16.0,9.0,4.5)$ & $5.63,1 \mathrm{H}, \mathrm{m}$ \\
\hline 7 & $5.22,1 \mathrm{H}, \mathrm{dd}(15.5,5.0)$ & $5.23,1 \mathrm{H}, \mathrm{dd}(15.5,5.0)$ & $5.25,1 \mathrm{H}, \mathrm{dd}(16.0,4.5)$ & $5.44,1 \mathrm{H}, \mathrm{dd}(15.5,4.0)$ \\
\hline 8 & $3.46,1 \mathrm{H}, \mathrm{dd}(8.5,5.0)$ & $3.48,1 \mathrm{H}, \mathrm{dd}(8.0,5.0)$ & $3.48,1 \mathrm{H}, \mathrm{dd}(8.5,5.0)$ & $4.02,1 \mathrm{H}, \mathrm{dd}(, 4.5)$ \\
\hline 9 & $3.02,1 \mathrm{H}, \mathrm{dd}(8.5,1.5)$ & $3.08,1 \mathrm{H}$, br.d $(8.5)$ & $3.05,1 \mathrm{H}$, br.d $(8.5)$ & $2.97^{*}, 1 \mathrm{H}, \mathrm{m}$ \\
\hline 10 & $2.91,1 \mathrm{H}, \mathrm{m}$ & $2.97,1 \mathrm{H}, \mathrm{m}$ & $2.94,1 \mathrm{H}, \mathrm{m}$ & $2.97^{*}, 1 \mathrm{H}, \mathrm{m}$ \\
\hline 11 & $5.62,1 \mathrm{H}, \mathrm{dd}(10.5,1.5)$ & $5.66,1 \mathrm{H}, \mathrm{d}(10.5)$ & $5.68,1 \mathrm{H}, \mathrm{d}(11.0)$ & $5.55,1 \mathrm{H}, \mathrm{dd}(10.5,1.0)$ \\
\hline 13 & $5.06,1 \mathrm{H}, \mathrm{d}(10.0)$ & $5.22,1 \mathrm{H}, \mathrm{d}(9.5)$ & $5.10,1 \mathrm{H}, \mathrm{d}(10.0)$ & $5.04,1 \mathrm{H}, \mathrm{d}(10.0)$ \\
\hline 14 & $2.95,1 \mathrm{H}, \mathrm{dd}(10.0,8.5)$ & $3.10,1 \mathrm{H}, \mathrm{m}$ & $2.96,1 \mathrm{H}, \mathrm{m}$ & $2.80,1 \mathrm{H}, \mathrm{m}$ \\
\hline \multirow[t]{2}{*}{16} & $2.48,2 \mathrm{H}, \mathrm{t}(7.0)$ & $6.35,1 \mathrm{H}, \mathrm{d}(15.5)$ & $2.57,1 \mathrm{H}, \mathrm{dd}(18.0,8.5)$ & $2.50,2 \mathrm{H}, \mathrm{m}$ \\
\hline & & & $2.66,1 \mathrm{H}, \mathrm{dd}(18.0,2.0)$ & \\
\hline 17 & $1.59,2 \mathrm{H}, \mathrm{m}$ & $6.82,1 \mathrm{H}, \mathrm{dt}(15.5,7.0)$ & $4.12,1 \mathrm{H}, \mathrm{t}$-like $(9.0)$ & $1.62,2 \mathrm{H}, \mathrm{m}$ \\
\hline \multirow[t]{2}{*}{18} & $1.32,2 \mathrm{H}, \mathrm{m}$ & $2.30,2 \mathrm{H}, \mathrm{m}$ & $1.36,1 \mathrm{H}, \mathrm{ddd}(14.0,9.0,4.0)$ & $1.35,2 \mathrm{H}, \mathrm{m}$ \\
\hline & & & $1.62,1 \mathrm{H}, \mathrm{m}$ & \\
\hline 19 & $2.10,1 \mathrm{H}, \mathrm{m}$ & $2.32,1 \mathrm{H}, \mathrm{m}$ & $2.50,1 \mathrm{H}, \mathrm{m}$ & $2.14,1 \mathrm{H}, \mathrm{m}$ \\
\hline \multirow[t]{2}{*}{20} & $2.20,1 \mathrm{H}, \mathrm{m}$ & $2.34,1 \mathrm{H}, \mathrm{m}$ & $2.32,1 \mathrm{H}, \mathrm{m}$ & $2.26,1 \mathrm{H}, \mathrm{m}$ \\
\hline & $2.66,1 \mathrm{H}, \mathrm{m}$ & $2.72,1 \mathrm{H}$, br.d $(13.5)$ & $2.80,1 \mathrm{H}, \mathrm{m}$ & $2.69,1 \mathrm{H}, \mathrm{m}$ \\
\hline 22 & $0.94,3 \mathrm{H}, \mathrm{d}(7.0)$ & $0.99,3 \mathrm{H}, \mathrm{d}(7.0)$ & $0.98,3 \mathrm{H}, \mathrm{d}(7.0)$ & $0.96, \mathrm{~d}(7.0)$ \\
\hline 23 & $1.83,3 \mathrm{H}, \mathrm{d}(1.5)$ & $1.86,3 \mathrm{H}$, br.s & $1.87,3 \mathrm{H}$, br.s & $1.86,3 \mathrm{H}, \mathrm{d}(1.5)$ \\
\hline 24 & $1.10,3 \mathrm{H}, \mathrm{d}(8.5)$ & $1.17,3 \mathrm{H}, \mathrm{d}(7.0)$ & $1.16,3 \mathrm{H}, \mathrm{d}(7.5)$ & $1.12,3 \mathrm{H}, \mathrm{d}(7.5)$ \\
\hline \multirow[t]{2}{*}{25} & $2.20,1 \mathrm{H}, \mathrm{m}$ & $2.34,1 \mathrm{H}, \mathrm{m}$ & $2.30,1 \mathrm{H}, \mathrm{m}$ & $2.26,1 \mathrm{H}, \mathrm{m}$ \\
\hline & $2.66,1 \mathrm{H}, \mathrm{m}$ & $2.72,1 \mathrm{H}$, br.d $(13.5)$ & $2.82,1 \mathrm{H}, \mathrm{m}$ & $2.69,1 \mathrm{H}, \mathrm{m}$ \\
\hline $8-\mathrm{OCH}_{3}$ & $3.28,3 \mathrm{H}, \mathrm{s}$ & $3.32,3 \mathrm{H}, \mathrm{s}$ & $3.32,3 \mathrm{H}, \mathrm{s}$ & \\
\hline $\mathrm{NH}$ & 8.40 , br.s & 7.79, br.s & 7.80 br.s & 8.33 br.s \\
\hline
\end{tabular}

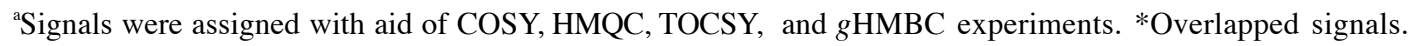




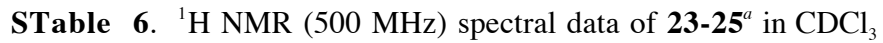

\begin{tabular}{|c|c|c|c|}
\hline Position & 23 & 24 & 25 \\
\hline 2 & $5.56,1 \mathrm{H}, \mathrm{dd}(16.0,2.0)$ & $5.56,1 \mathrm{H}, \mathrm{dd}(16.0,1.5)$ & $5.56,1 \mathrm{H}, \mathrm{dd}(15.5,1.5)$ \\
\hline 3 & $6.49,1 \mathrm{H}, \mathrm{ddd}(16.0,11.0,3.5)$ & $6.47,1 \mathrm{H}$, ddd $(16.0,10.0,3.0)$ & $6.46,1 \mathrm{H}$, ddd $(16.0,10.5,3.5)$ \\
\hline \multirow[t]{2}{*}{4} & $2.12,1 \mathrm{H}, \mathrm{m}$ & $2.15,1 \mathrm{H}, \mathrm{m}$ & $2.10,1 \mathrm{H}, \mathrm{m}$ \\
\hline & $2.46,1 \mathrm{H}, \mathrm{m}$ & $2.40,1 \mathrm{H}, \mathrm{m}$ & $2.42,1 \mathrm{H}, \mathrm{m}$ \\
\hline \multirow[t]{2}{*}{5} & $2.10,1 \mathrm{H}, \mathrm{m}$ & $2.15,1 \mathrm{H}, \mathrm{m}$ & $2.081 \mathrm{H}, \mathrm{m}$ \\
\hline & $2.38,1 \mathrm{H}, \mathrm{m}$ & $2.40,1 \mathrm{H}, \mathrm{m}$ & $2.34,1 \mathrm{H}, \mathrm{m}$ \\
\hline 6 & $5.26^{*}, 1 \mathrm{H}, \mathrm{m}$ & $5.26^{*}, 1 \mathrm{H}, \mathrm{m}$ & $5.25^{*}, 1 \mathrm{H}, \mathrm{m}$ \\
\hline 7 & $5.26^{*}, 1 \mathrm{H}, \mathrm{m}$ & $5.26^{*}, 1 \mathrm{H}, \mathrm{m}$ & $5.25^{*}, 1 \mathrm{H}, \mathrm{m}$ \\
\hline 8 & $2.18,2 \mathrm{H}, \mathrm{m}$ & $2.19,2 \mathrm{H}, \mathrm{m}$ & $2.18,2 \mathrm{H}, \mathrm{m}$ \\
\hline 9 & $3.29,1 \mathrm{H}$, td-like $(8.5,1.5)$ & $3.28,1 \mathrm{H}, \mathrm{dd}(8.5,1.5)$ & $3.31,1 \mathrm{H}$, td-like $(8.0,1.5)$ \\
\hline 10 & $2.94,1 \mathrm{H}, \mathrm{m}$ & $2.95,1 \mathrm{H}, \mathrm{m}$ & $2.99,1 \mathrm{H}, \mathrm{m}$ \\
\hline 11 & $5.56,1 \mathrm{H}, \mathrm{dd}(11.5,1.5)$ & $5.54,1 \mathrm{H}, \mathrm{dd}(10.0,1.5)$ & $5.54,1 \mathrm{H}, \mathrm{dd}(11.0,1.0)$ \\
\hline 13 & $5.04,1 \mathrm{H}, \mathrm{d}(11.0)$ & $5.03,1 \mathrm{H}, \mathrm{d}(10.5)$ & $5.13,1 \mathrm{H}, \mathrm{d}(10.0)$ \\
\hline 14 & $3.00,1 \mathrm{H}, \mathrm{m}$ & $3.00,1 \mathrm{H}, \mathrm{dd}(10.5,7.0)$ & $3.15,1 \mathrm{H}, \mathrm{m}$ \\
\hline \multirow[t]{2}{*}{16} & $2.58,1 \mathrm{H}, \mathrm{dd}(18.0,9.0)$ & $2.52,2 \mathrm{H}, \mathrm{m}$ & $6.35,1 \mathrm{H}, \mathrm{d}(15.5)$ \\
\hline & $2.68,1 \mathrm{H}, \mathrm{dd}(18.0,3.0)$ & & $6.82,1 \mathrm{H}, \mathrm{dt}(15.5,7.0)$ \\
\hline 17 & $4.13,1 \mathrm{H}, \mathrm{t}$-like $(9.5)$ & $1.63,2 \mathrm{H}, \mathrm{m}$ & $2.30,2 \mathrm{H}, \mathrm{m}$ \\
\hline \multirow[t]{2}{*}{18} & $1.37,1 \mathrm{H}$, ddd $(14.0,9.0,3.0)$ & $1.36,2 \mathrm{H}, \mathrm{m}$ & $2.30,2 \mathrm{H}, \mathrm{m}$ \\
\hline & $1.63,1 \mathrm{H}, \mathrm{ddd}(14.0,10.5,5.0)$ & & \\
\hline 19 & $2.50,1 \mathrm{H}, \mathrm{m}$ & $2.10,1 \mathrm{H}, \mathrm{m}$ & $2.34,1 \mathrm{H}, \mathrm{m}$ \\
\hline \multirow[t]{2}{*}{20} & $2.34,1 \mathrm{H}, \mathrm{m}$ & $2.25,1 \mathrm{H}, \mathrm{m}$ & $2.34,1 \mathrm{H}, \mathrm{m}$ \\
\hline & $2.76,1 \mathrm{H}, \mathrm{m}$ & $2.70, \mathrm{H}, \mathrm{m}$ & $2.72,1 \mathrm{H}, \mathrm{m}$ \\
\hline 22 & $0.95,3 \mathrm{H}, \mathrm{d}(7.0)$ & $0.94,3 \mathrm{H}, \mathrm{d}(7.0)$ & $0.96,3 \mathrm{H}, \mathrm{d}(7.0)$ \\
\hline 23 & $1.89,3 \mathrm{H}, \mathrm{d}(1.5)$ & $1.88,3 \mathrm{H}, \mathrm{d}(1.5)$ & $1.89,3 \mathrm{H}, \mathrm{d}(1.0)$ \\
\hline 24 & $1.17,3 \mathrm{H}, \mathrm{d}(7.0)$ & $1.13,3 \mathrm{H}, \mathrm{d}(7.5)$ & $1.18,3 \mathrm{H}, \mathrm{d}(7.0)$ \\
\hline \multirow[t]{2}{*}{25} & $2.32,1 \mathrm{H}, \mathrm{m}$ & $2.25,1 \mathrm{H}, \mathrm{m}$ & $2.36,1 \mathrm{H}, \mathrm{m}$ \\
\hline & $2.78,1 \mathrm{H}, \mathrm{m}$ & $2.70,1 \mathrm{H}, \mathrm{m}$ & $2.72,1 \mathrm{H}, \mathrm{m}$ \\
\hline $\mathrm{NH}$ & 7.82 br.s & & 7.87 br.s \\
\hline
\end{tabular}

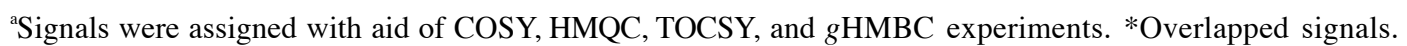


STable 7. ${ }^{13} \mathrm{C}$ NMR (125 MHz) spectral data of $\mathbf{1}$ and $\mathbf{2 0 - 2 5}{ }^{a}$ in $\mathrm{CDCl}_{3}$

\begin{tabular}{|c|c|c|c|c|c|c|c|}
\hline Position & 1 & 20 & 21 & 22 & 23 & 24 & 25 \\
\hline 1 & 164.0 & 164.3 & 164.2 & 164.1 & 164.2 & 164.2 & 164.3 \\
\hline 2 & 122.3 & 122.4 & 122.2 & 122.3 & 122.0 & 122.2 & 122.2 \\
\hline 3 & 150.1 & 150.1 & 150.5 & 150.5 & 151.0 & 150.6 & 150.6 \\
\hline 4 & 30.5 & 30.3 & 30.4 & $30.5^{*}$ & 30.7 & $30.6^{*}$ & 30.6 \\
\hline 5 & 31.2 & 31.4 & 31.4 & 31.1 & 31.3 & 31.2 & 31.3 \\
\hline 6 & 130.6 & 130.9 & 130.9 & 129.0 & 132.0 & 132.1 & 132.1 \\
\hline 7 & 128.1 & 128.3 & 128.3 & 131.4 & 128.4 & 127.6 & 128.4 \\
\hline 8 & 82.7 & 82.8 & 82.7 & 72.3 & 38.1 & 38.1 & 38.1 \\
\hline 9 & 78.0 & 78.1 & 78.2 & 79.7 & 76.2 & 76.2 & 76.2 \\
\hline 10 & 32.1 & 32.3 & 32.3 & 32.7 & 33.2 & 33.2 & 33.2 \\
\hline 11 & 133.2 & 133.4 & 133.7 & 132.9 & 133.6 & 133.3 & 133.3 \\
\hline 12 & 131.3 & 131.3 & 131.2 & 131.9 & 132.2 & 132.2 & 132.2 \\
\hline 13 & 77.1 & 76.9 & $77.2^{b}$ & 77.3 & $77.2^{b}$ & 77.0 & $77.2^{b}$ \\
\hline 14 & 51.2 & 49.9 & 52.0 & 51.3 & 51.9 & 51.4 & 49.7 \\
\hline 15 & 211.0 & 199.8 & 213.1 & 211.0 & 213.1 & 211.1 & 199.9 \\
\hline 16 & 40.3 & 130.5 & 47.6 & 40.4 & 47.8 & 40.4 & 130.6 \\
\hline 17 & 20.3 & 142.3 & 65.0 & 20.3 & 65.0 & 20.4 & 142.3 \\
\hline 18 & 34.3 & $37.6 *$ & 40.9 & 34.3 & 40.9 & 34.4 & $37.6^{*}$ \\
\hline 19 & 30.2 & 30.0 & 27.4 & $30.5^{*}$ & 27.3 & $30.6^{*}$ & 29.9 \\
\hline 20 & $37.8 *$ & $37.6 *$ & 38.7 & 37.9 & 38.7 & 37.9 & $37.6 *$ \\
\hline 21 & 172.5 & 171.1 & 172.1 & 172.4 & 172.1 & $172.1 *$ & $171.2 *$ \\
\hline 22 & $13.5 *$ & 13.6 & 13.6 & 13.3 & 11.9 & 11.9 & 11.9 \\
\hline 23 & 26.1 & 26.0 & 26.3 & 26.2 & 26.5 & 26.4 & 26.3 \\
\hline 24 & $13.5 *$ & 13.4 & 13.5 & 13.6 & 13.6 & 13.6 & 13.6 \\
\hline 25 & $37.8 *$ & $37.5 *$ & 37.4 & 37.9 & 37.4 & 37.9 & $37.5 *$ \\
\hline 26 & 172.5 & 171.1 & 172.0 & 172.4 & 171.9 & $172.1 *$ & $171.2 *$ \\
\hline $8-\mathrm{OCH}_{3}$ & 57.0 & 57.1 & 57.2 & & & & \\
\hline
\end{tabular}

${ }^{a}$ Signals were assigned with aid of COSY, HMQC, TOCSY, and $g$ HMBC experiments. ${ }^{b}$ Signals were overlapped with solvent peak but can be resolved by HMQC experiment. *Overlapped signals. 
STable 8. ${ }^{1} \mathrm{H}$ NMR (500 MHz) spectral data of 27, 28, 30, and 34 in MeOH- $d_{4}$

\begin{tabular}{|c|c|c|c|c|}
\hline Position & $27^{a}$ & $28^{a}$ & $30^{a}$ & $34^{a}$ \\
\hline 2 & $5.85,1 \mathrm{H}, \mathrm{d}(15.5)$ & $5.84,1 \mathrm{H}, \mathrm{d}(15.5)$ & $5.85,1 \mathrm{H}, \mathrm{d}(15.5)$ & $5.84,1 \mathrm{H}, \mathrm{d}(15.0)$ \\
\hline 3 & $6.88,1 \mathrm{H}, \mathrm{dt}(15.5,7.0)$ & $6.86,1 \mathrm{H}, \mathrm{dt}(15.5,7.0)$ & $6.88,1 \mathrm{H}, \mathrm{dt}(15.5,7.0)$ & $6.87,1 \mathrm{H}, \mathrm{dt}(15.5,6.5)$ \\
\hline 4 & $2.36,2 \mathrm{H}, \mathrm{m}$ & $2.31,2 \mathrm{H}, \mathrm{m}$ & $2.30,2 \mathrm{H}, \mathrm{m}$ & $2.34,2 \mathrm{H}, \mathrm{m}$ \\
\hline 5 & $2.24,2 \mathrm{H}, \mathrm{m}$ & $2.24,2 \mathrm{H}, \mathrm{m}$ & $2.17,2 \mathrm{H}, \mathrm{m}$ & $2.30,2 \mathrm{H}, \mathrm{m}$ \\
\hline 6 & $5.72,1 \mathrm{H}, \mathrm{dt}(15.5,6.0)$ & $5.72,1 \mathrm{H}, \mathrm{dt}(15.5,6.5)$ & $5.53 *, 1 \mathrm{H}, \mathrm{m}$ & $5.74,1 \mathrm{H}, \mathrm{dt}(15.5,6.0)$ \\
\hline 7 & $5.50,1 \mathrm{H}, \mathrm{dd}(15.5,8.0)$ & $5.62,1 \mathrm{H}, \mathrm{dd}(15.5,7.0)$ & $5.53^{*}, 1 \mathrm{H}, \mathrm{m}$ & $5.61,1 \mathrm{H}, \mathrm{dd}(15.5,7.0)$ \\
\hline \multirow[t]{2}{*}{8} & $3.55,1 \mathrm{H}, \mathrm{dd}(8.5,4.0)$ & $4.00 *, 1 \mathrm{H}, \mathrm{m}$ & $2.00,1 \mathrm{H}, \mathrm{m}$ & $3.87,1 \mathrm{H}, \mathrm{dd}(6.5,3.5)$ \\
\hline & & & $2.30,1 \mathrm{H}, \mathrm{m}$ & \\
\hline 9 & $3.19,1 \mathrm{H}, \mathrm{dd}(9.0,4.0)$ & $3.20,1 \mathrm{H}, \mathrm{dd}(7.0,4.0)$ & $3.35,1 \mathrm{H}, \mathrm{td}(8.0,4.0)$ & $3.11,1 \mathrm{H}, \mathrm{dd}(7.5,3.5)$ \\
\hline 10 & $2.74,1 \mathrm{H}, \mathrm{m}$ & $2.64,1 \mathrm{H}, \mathrm{m}$ & $2.46,1 \mathrm{H}, \mathrm{m}$ & $2.70,1 \mathrm{H}, \mathrm{m}$ \\
\hline 11 & $5.30,1 \mathrm{H}, \mathrm{d}(11.0)$ & $5.31,1 \mathrm{H}, \mathrm{d}(8.5)$ & $5.27,1 \mathrm{H}, \mathrm{d}(11.0)$ & $5.25,1 \mathrm{H}, \mathrm{d}(10.0)$ \\
\hline 13 & $4.03,1 \mathrm{H}, \mathrm{d}(10.0)$ & $4.00^{*}, 1 \mathrm{H}, \mathrm{m}$ & $4.01,1 \mathrm{H}, \mathrm{d}(10.0)$ & $4.15,1 \mathrm{H}, \mathrm{d}(7.0)$ \\
\hline 14 & $2.80,1 \mathrm{H}, \mathrm{m}$ & $2.77,1 \mathrm{H}, \mathrm{m}$ & $2.77,1 \mathrm{H}, \mathrm{m}$ & $2.82,1 \mathrm{H}$, quintet $(7.0)$ \\
\hline 16 & $1.52,2 \mathrm{H}, \mathrm{m}$ & $2.63,2 \mathrm{H}, \mathrm{m}$ & $2.65,2 \mathrm{H}, \mathrm{m}$ & $2.55,2 \mathrm{H}, \mathrm{m}$ \\
\hline 17 & $4.18,1 \mathrm{H}, \mathrm{m}$ & $1.61,2 \mathrm{H}, \mathrm{m}$ & $1.61,2 \mathrm{H}, \mathrm{m}$ & $1.56,2 \mathrm{H}, \mathrm{m}$ \\
\hline \multirow[t]{2}{*}{18} & $2.74,1 \mathrm{H}, \mathrm{m}$ & $1.38,2 \mathrm{H}, \mathrm{m}$ & $1.38,2 \mathrm{H}, \mathrm{m}$ & $1.38,2 \mathrm{H}, \mathrm{m}$ \\
\hline & $2.82,1 \mathrm{H}, \mathrm{m}$ & & & \\
\hline 19 & $2.40,1 \mathrm{H}, \mathrm{m}$ & $2.13,1 \mathrm{H}, \mathrm{m}$ & $2.18,1 \mathrm{H}, \mathrm{m}$ & $2.12,1 \mathrm{H}, \mathrm{m}$ \\
\hline \multirow[t]{2}{*}{20} & $2.38,1 \mathrm{H}, \mathrm{m}$ & $2.32,1 \mathrm{H}, \mathrm{m}$ & $2.32,1 \mathrm{H}, \mathrm{m}$ & $2.30,1 \mathrm{H}, \mathrm{m}$ \\
\hline & $2.78,1 \mathrm{H}, \mathrm{m}$ & $2.64,1 \mathrm{H}, \mathrm{m}$ & $2.68,1 \mathrm{H}, \mathrm{m}$ & $2.68,1 \mathrm{H}, \mathrm{m}$ \\
\hline 22 & $0.98,3 \mathrm{H}, \mathrm{d}(7.0)$ & $0.99,3 \mathrm{H}, \mathrm{d}(7.0)$ & $0.98,3 \mathrm{H}, \mathrm{d}(7.0)$ & $0.99,3 \mathrm{H}, \mathrm{d}(6.5)$ \\
\hline 23 & $1.63,3 \mathrm{H}, \mathrm{d}(1.5)$ & $1.64,3 \mathrm{H}, \mathrm{d}(1.0)$ & $1.62,3 \mathrm{H}, \mathrm{d}(1.5)$ & $1.65,3 \mathrm{H}, \mathrm{d}(1.0)$ \\
\hline 24 & $0.85,3 \mathrm{H}, \mathrm{d}(6.5)$ & $0.82,3 \mathrm{H}, \mathrm{d}(7.0)$ & $0.82,3 \mathrm{H}, \mathrm{d}(7.0)$ & $1.07,3 \mathrm{H}, \mathrm{d}(7.0)$ \\
\hline \multirow[t]{2}{*}{25} & $2.40,1 \mathrm{H}, \mathrm{m}$ & $2.32,1 \mathrm{H}, \mathrm{m}$ & $2.32,1 \mathrm{H}, \mathrm{m}$ & $2.30,1 \mathrm{H}, \mathrm{m}$ \\
\hline & $2.70,1 \mathrm{H}, \mathrm{m}$ & $2.64,1 \mathrm{H}, \mathrm{m}$ & $2.68,1 \mathrm{H}, \mathrm{m}$ & $2.68,1 \mathrm{H}, \mathrm{m}$ \\
\hline $8-\mathrm{OCH}_{3}$ & $3.20,3 \mathrm{H}, \mathrm{s}$ & & & \\
\hline
\end{tabular}

${ }^{a}$ Signals were assigned with aid of COSY, HMQC and $g$ HMBC experiments. *Overlapped signals. 
STable 9. ${ }^{1} \mathrm{H}$ NMR (500 MHz) spectral data of 36, 39, 40, and 42 in $\mathrm{MeOH}-d_{4}$

\begin{tabular}{|c|c|c|c|c|}
\hline Position & $36^{a}$ & $39^{a}$ & $40^{a}$ & $42^{a}$ \\
\hline 2 & $5.85,1 \mathrm{H}, \mathrm{d}(16.0)$ & $5.85,1 \mathrm{H}, \mathrm{d}(15.5)$ & $5.84,1 \mathrm{H}, \mathrm{d}(15.5)$ & $5.81,1 \mathrm{H}, \mathrm{d}(15.5)$ \\
\hline 3 & $6.80,1 \mathrm{H}, \mathrm{dt}(16.0,6.5)$ & $6.92,1 \mathrm{H}, \mathrm{dt}(15.5,7.0)$ & $6.82,1 \mathrm{H}, \mathrm{dt}(15.5,6.5)$ & $6.94,1 \mathrm{H}, \mathrm{dt}(15.5,7.0)$ \\
\hline 4 & $2.20,2 \mathrm{H}, \mathrm{m}$ & $2.36,2 \mathrm{H}, \mathrm{m}$ & $2.32,2 \mathrm{H}, \mathrm{m}$ & $2.32,2 \mathrm{H}, \mathrm{m}$ \\
\hline 5 & $2.28,2 \mathrm{H}, \mathrm{m}$ & $2.30,2 \mathrm{H}, \mathrm{m}$ & $2.26,2 \mathrm{H}, \mathrm{m}$ & $2.20,2 \mathrm{H}, \mathrm{m}$ \\
\hline 6 & $5.52^{*}, 1 \mathrm{H}, \mathrm{m}$ & $5.79,1 \mathrm{H}, \mathrm{dt}(15.5,7.0)$ & $5.76,1 \mathrm{H}, \mathrm{dt}(15.5,6.5)$ & $5.50^{*}, 1 \mathrm{H}, \mathrm{m}$ \\
\hline 7 & $5.52^{*}, 1 \mathrm{H}, \mathrm{m}$ & $5.25,1 \mathrm{H}, \mathrm{dd}(15.5,7.0)$ & $5.46,1 \mathrm{H}, \mathrm{dd}(15.5,8.0)$ & $5.50^{*}, 1 \mathrm{H}, \mathrm{m}$ \\
\hline \multirow[t]{2}{*}{8} & $1.98,1 \mathrm{H}, \mathrm{m}$ & $3.50^{*}, 1 \mathrm{H}, \mathrm{m}$ & $3.98^{*}, 1 \mathrm{H}, \mathrm{m}$ & $2.25,2 \mathrm{H}, \mathrm{m}$ \\
\hline & $2.22,1 \mathrm{H}, \mathrm{m}$ & & & \\
\hline 9 & $3.27,1 \mathrm{H}, \mathrm{td}(8.0,3.5)$ & $3.46,1 \mathrm{H}, \mathrm{dd}(8.5,2.0)$ & $3.30^{b}, 1 \mathrm{H}, \mathrm{m}$ & $3.59,1 \mathrm{H}, \mathrm{td}(8.0,3.0)$ \\
\hline 10 & $2.42,1 \mathrm{H}, \mathrm{m}$ & $1.75,1 \mathrm{H}, \mathrm{m}$ & $1.79,1 \mathrm{H}, \mathrm{dt}(7.0,2.5)$ & $1.70,1 \mathrm{H}, \mathrm{m}$ \\
\hline 11 & $5.23,1 \mathrm{H}, \mathrm{d}(10.0)$ & $3.94,1 \mathrm{H}, \mathrm{d}(8.5)$ & $3.98^{*}, 1 \mathrm{H}, \mathrm{m}$ & $4.03,1 \mathrm{H}, \mathrm{d}(6.5)$ \\
\hline 13 & $4.16,1 \mathrm{H}, \mathrm{d}(7.5)$ & $5.25,1 \mathrm{H}, \mathrm{d}(8.5)$ & $5.31,1 \mathrm{H}, \mathrm{d}(10.0)$ & $5.32,1 \mathrm{H}, \mathrm{d}(9.5)$ \\
\hline 14 & $2.81,1 \mathrm{H}$, quintet $(7.0)$ & $3.50^{*}, 1 \mathrm{H}, \mathrm{m}$ & $3.52,1 \mathrm{H}, \mathrm{m}$ & $3.52,1 \mathrm{H}, \mathrm{m}$ \\
\hline 16 & $2.57,2 \mathrm{H}, \mathrm{m}$ & $1.60,2 \mathrm{H}, \mathrm{m}$ & $2.52,2 \mathrm{H}, \mathrm{m}$ & $2.52,2 \mathrm{H}, \mathrm{m}$ \\
\hline 17 & $1.55,2 \mathrm{H}, \mathrm{m}$ & $4.14,1 \mathrm{H}, \mathrm{m}$ & $1.58,2 \mathrm{H}, \mathrm{m}$ & $1.57,2 \mathrm{H}, \mathrm{m}$ \\
\hline \multirow[t]{2}{*}{18} & $1.35,2 \mathrm{H}, \mathrm{m}$ & $2.49,1 \mathrm{H}, \mathrm{dd}(17.5,4.0)$ & $1.37,2 \mathrm{H}, \mathrm{m}$ & $1.35,2 \mathrm{H}, \mathrm{m}$ \\
\hline & & $2.70,1 \mathrm{H}, \mathrm{m}$ & & \\
\hline 19 & $2.13,1 \mathrm{H}, \mathrm{m}$ & $2.38,1 \mathrm{H}, \mathrm{m}$ & $2.16,1 \mathrm{H}, \mathrm{m}$ & $2.20,1 \mathrm{H}, \mathrm{m}$ \\
\hline \multirow[t]{2}{*}{20} & $2.32,1 \mathrm{H}, \mathrm{m}$ & $2.36,1 \mathrm{H}, \mathrm{m}$ & $2.34,1 \mathrm{H}, \mathrm{m}$ & $2.32,1 \mathrm{H}, \mathrm{m}$ \\
\hline & $2.66,1 \mathrm{H}, \mathrm{m}$ & $2.78,1 \mathrm{H}, \mathrm{m}$ & $2.64,1 \mathrm{H}, \mathrm{dd}(17.0,4.5)$ & $2.64,1 \mathrm{H}, \mathrm{m}$ \\
\hline 22 & $0.99,3 \mathrm{H}, \mathrm{d}(7.0)$ & $0.94,3 \mathrm{H}, \mathrm{d}(7.0)$ & $0.92,3 \mathrm{H}, \mathrm{d}(7.0)$ & $0.89,3 \mathrm{H}, \mathrm{d}(7.0)$ \\
\hline 23 & $1.63,3 \mathrm{H}, \mathrm{d}(1.0)$ & $1.68,3 \mathrm{H}, \mathrm{d}(1.5)$ & $1.67,3 \mathrm{H}, \mathrm{d}(1.0)$ & $1.65,3 \mathrm{H}, \mathrm{d}(1.5)$ \\
\hline 24 & $1.07,3 \mathrm{H}, \mathrm{d}(7.0)$ & $1.11,3 \mathrm{H}, \mathrm{d}(6.5)$ & $1.12,3 \mathrm{H}, \mathrm{d}(6.5)$ & $1.12,3 \mathrm{H}, \mathrm{d}(6.5)$ \\
\hline \multirow[t]{2}{*}{25} & $2.32,1 \mathrm{H}, \mathrm{m}$ & $2.38,1 \mathrm{H}, \mathrm{m}$ & $2.34,1 \mathrm{H}, \mathrm{m}$ & $2.32,1 \mathrm{H}, \mathrm{m}$ \\
\hline & $2.66,1 \mathrm{H}, \mathrm{m}$ & $2.70,1 \mathrm{H}, \mathrm{m}$ & $2.64,1 \mathrm{H}, \mathrm{dd}(17.0,4.5)$ & $2.64,1 \mathrm{H}, \mathrm{m}$ \\
\hline $8-\mathrm{OCH}_{3}$ & & $3.30,3 \mathrm{H}, \mathrm{s}$ & & \\
\hline
\end{tabular}

${ }^{a}$ Signals were assigned with aid of COSY, HMQC and $g$ HMBC experiments. *Overlapped signals. ${ }^{b}$ Overlapped with solvent peak. 
STable $10{ }^{13} \mathrm{C}$ NMR (125 MHz) spectral data of 28, 30, 34, 36, 39, 40, and 42 in $\mathrm{MeOH}-d_{4}$

\begin{tabular}{|c|c|c|c|c|c|c|c|}
\hline position & $28^{a}$ & $30^{a}$ & $34^{a}$ & $36^{a}$ & $39^{a}$ & $40^{a}$ & $42^{a}$ \\
\hline 1 & \# & \# & \# & \# & $\#$ & $168.0^{b}$ & 170.2 \\
\hline 2 & $123.6^{b}$ & \# & $123.8^{b}$ & \# & \# & $124.6^{b}$ & 123.1 \\
\hline 3 & 147.4 & $148.0^{b}$ & $147.0^{b}$ & $146.6^{b}$ & $149.4^{b}$ & $146.4^{b}$ & 150.6 \\
\hline 4 & 32.9 & 33.2 & 32.9 & 32.7 & 32.8 & 32.8 & 33.2 \\
\hline 5 & 32.3 & 32.6 & 32.3 & 33.2 & 32.1 & 32.3 & 32.4 \\
\hline 6 & 132.3 & 132.4 & 132.1 & 132.7 & 136.6 & 133.7 & 132.7 \\
\hline 7 & 133.3 & 129.5 & 133.6 & 129.4 & 129.1 & 132.2 & 129.1 \\
\hline 8 & 74.5 & 39.2 & 74.3 & 39.5 & 86.4 & 75.5 & 39.5 \\
\hline 9 & 79.3 & 76.7 & 79.6 & 76.9 & 75.5 & 77.1 & 74.3 \\
\hline 10 & 36.0 & 39.3 & 36.0 & 39.6 & 38.6 & 38.5 & 40.3 \\
\hline 11 & 133.8 & 133.6 & 131.7 & 131.7 & 81.1 & 80.4 & 80.3 \\
\hline 12 & 136.0 & 136.1 & 136.5 & 136.3 & 140.6 & 140.4 & 140.6 \\
\hline 13 & 82.1 & 82.1 & 79.0 & 78.8 & 128.0 & 127.7 & 127.0 \\
\hline 14 & 50.4 & 50.4 & 51.3 & 51.3 & 47.8 & 47.3 & 47.2 \\
\hline 15 & 216.8 & 216.8 & 215.0 & 215.1 & 211.0 & 214.1 & 214.1 \\
\hline 16 & 43.8 & 43.8 & 42.7 & 42.6 & 42.8 & 41.5 & 41.4 \\
\hline 17 & 21.2 & 21.3 & 21.5 & 21.4 & 66.0 & 21.7 & 21.7 \\
\hline 18 & 35.4 & 35.4 & 35.4 & 35.4 & 38.6 & 95.4 & 35.5 \\
\hline 19 & 31.7 & 31.7 & 31.8 & 31.8 & 28.8 & 31.7 & 31.7 \\
\hline 20 & $38.7 *$ & $38.7 *$ & $38.7 *$ & $38.7 *$ & 39.4 & $38.6 *$ & $38.7 *$ \\
\hline 21 & $175.8 *$ & $175.7 *$ & $175.6 *$ & $175.6 *$ & 175.7 & $175.8 *$ & $175.7 *$ \\
\hline 22 & 16.5 & 16.9 & 16.7 & 17.1 & 8.8 & 8.6 & 7.7 \\
\hline 23 & 11.0 & 11.2 & 12.9 & 13.0 & 12.1 & 12.7 & 13.1 \\
\hline 24 & 14.6 & 14.6 & 12.6 & 12.6 & 16.0 & 16.7 & 16.7 \\
\hline 25 & $38.7 *$ & $38.7 *$ & $38.7 *$ & $38.7 *$ & 38.1 & $38.6^{*}$ & $38.7 *$ \\
\hline 26 & $175.8 *$ & $175.7 *$ & $175.6 *$ & $175.6^{*}$ & 175.5 & $175.8 *$ & $175.7 *$ \\
\hline $8-\mathrm{OCH}_{3}$ & & & & & 56.7 & & \\
\hline
\end{tabular}

${ }^{a}$ Signals were assigned with aid of COSY, HMQC and $g \mathrm{HMBC}$ experiments. ${ }^{b}$ Signals were assigned on the basis of HMQC or gHMBC experiment only. \# not observed. *Overlapped signals. 
STable 11. Cysteine 1, 4-Michael addition products of 10, 13, 14, 17, 19 and their LC-MS data (acquired in both positive and negative mode)

\begin{tabular}{|l|l|l|}
\hline 10 or its congener & \multicolumn{2}{|c|}{ Products } \\
\hline $\mathbf{1 0}$ & $\mathbf{4 4}$ & $\mathbf{4 5}$ \\
& $m / z 476.2([\mathrm{M}+\mathrm{H}])^{+} ;$ & $m / z 476.2([\mathrm{M}+\mathrm{H}])^{+} ;$ \\
& $m / z 476.2([\mathrm{M}-\mathrm{H}])^{-}$ & $m / z 476.2([\mathrm{M}-\mathrm{H}])^{-}$ \\
\hline $\mathbf{1 3}$ & $\mathbf{5}$ & $\mathbf{6}$ \\
& $m / z 627.0([\mathrm{M}+\mathrm{H}])^{+} ;$ & $m / z 626.9([\mathrm{M}+\mathrm{H}])^{+} ;$ \\
& $m / z 625.3([\mathrm{M}-\mathrm{H}])^{-}$ & $m / z 625.3([\mathrm{M}-\mathrm{H}])^{-}$ \\
\hline $\mathbf{1 4}$ & $\mathbf{4 6}$ & $\mathbf{4 7}$ \\
& $m / z 597.0([\mathrm{M}+\mathrm{H}])^{+} ;$ & $m / z 597.0([\mathrm{M}+\mathrm{H}])^{+} ;$ \\
& $m / z 595.2([\mathrm{M}-\mathrm{H}])^{-}$ & $m / z 595.2([\mathrm{M}-\mathrm{H}])^{-}$ \\
\hline $\mathbf{1 7}$ & $\mathbf{4 8}$ & $\mathbf{4 9}$ \\
& $m / z 579.2([\mathrm{M}+\mathrm{H}])^{+} ;$ & $m / z 579.2([\mathrm{M}+\mathrm{H}])^{+} ;$ \\
& $m / z 581.0([\mathrm{M}-\mathrm{H}])^{-}$ & $m / z 581.0([\mathrm{M}-\mathrm{H}])^{-}$ \\
\hline 19 & $\mathbf{5 0}$ & $\mathbf{5 1}$ \\
& $m / z 596.9([\mathrm{M}+\mathrm{H}])^{+} ;$ & $m / z 597.0([\mathrm{M}+\mathrm{H}])^{+} ;$ \\
& $m / z 595.2([\mathrm{M}-\mathrm{H}])^{-}$ & $m / z 595.2([\mathrm{M}-\mathrm{H}])^{-}$ \\
\hline
\end{tabular}


STable $12{ }^{1} \mathrm{H}$ NMR (500 MHz) spectral data of compounds 44 and 45 in $\mathrm{MeOH}-d_{4}$

\begin{tabular}{|c|c|c|}
\hline Position & $44^{a}$ & $45^{a}$ \\
\hline \multirow[t]{2}{*}{2} & $2.54,1 \mathrm{H}, \mathrm{dd}(18.0,11.0)$ & $2.38^{*}, 1 \mathrm{H}, \mathrm{m}$ \\
\hline & $2.77,1 \mathrm{H}, \mathrm{dd}(18.0,3.0)$ & $2.95^{*}, 1 \mathrm{H}, \mathrm{m}$ \\
\hline 3 & $3.40,1 \mathrm{H}, \mathrm{m}$ & $3.13,1 \mathrm{H}, \mathrm{m}$ \\
\hline \multirow[t]{2}{*}{4} & $1.90,1 \mathrm{H}, \mathrm{m}$ & $1.60,1 \mathrm{H}, \mathrm{m}$ \\
\hline & $2.18,1 \mathrm{H}, \mathrm{m}$ & $1.82,1 \mathrm{H}, \mathrm{m}$ \\
\hline 5 & $2.23,2 \mathrm{H}, \mathrm{m}$ & $2.24,2 \mathrm{H}, \mathrm{m}$ \\
\hline 6 & $5.71,1 \mathrm{H}, \mathrm{ddd}(15.5,10.0,6.5)$ & $5.74,1 \mathrm{H}, \mathrm{ddd}(15.5,10.0,7.0)$ \\
\hline 7 & $5.38,1 \mathrm{H}, \mathrm{dd}(15.5,6.5)$ & $5.35,1 \mathrm{H}, \mathrm{dd}(15.5,7.0)$ \\
\hline 8 & $3.35^{*}, 1 \mathrm{H}, \mathrm{m}$ & $3.40,1 \mathrm{H}, \mathrm{dd}(9.0,7.0)$ \\
\hline 9 & $3.64,1 \mathrm{H}, \mathrm{d}(9.0)$ & $3.68,1 \mathrm{H}, \mathrm{d}(9.0)$ \\
\hline 10 & $2.04,1 \mathrm{H}, \mathrm{m}$ & $2.14,1 \mathrm{H}, \mathrm{m}$ \\
\hline 11 & $4.99,1 \mathrm{H}, \mathrm{d}(3.5)$ & $5.10,1 \mathrm{H}, \mathrm{d}(3.0)$ \\
\hline 13 & $5.15,1 \mathrm{H}, \mathrm{d}(10.0)$ & $5.15,1 \mathrm{H}, \mathrm{d}(10.0)$ \\
\hline 14 & $3.53,1 \mathrm{H}, \mathrm{m}$ & $3.53,1 \mathrm{H}, \mathrm{m}$ \\
\hline \multirow[t]{2}{*}{16} & $2.48,1 \mathrm{H}, \mathrm{m}$ & $2.48,1 \mathrm{H}, \mathrm{m}$ \\
\hline & $2.68,1 \mathrm{H}, \mathrm{m}$ & $2.66,1 \mathrm{H}, \mathrm{m}$ \\
\hline 17 & $1.56,2 \mathrm{H}, \mathrm{m}$ & $1.56,2 \mathrm{H}, \mathrm{m}$ \\
\hline 18 & $1.34,2 \mathrm{H}, \mathrm{m}$ & $1.34,2 \mathrm{H}, \mathrm{m}$ \\
\hline 19 & $2.20,1 \mathrm{H}, \mathrm{m}$ & $2.20,1 \mathrm{H}, \mathrm{m}$ \\
\hline \multirow[t]{2}{*}{20} & $2.32,1 \mathrm{H}, \mathrm{m}$ & $2.33,1 \mathrm{H}, \mathrm{m}$ \\
\hline & $2.68,1 \mathrm{H}, \mathrm{m}$ & $2.68,1 \mathrm{H}, \mathrm{m}$ \\
\hline 22 & $0.91,3 \mathrm{H}, \mathrm{d}(7.5)$ & $0.92,3 \mathrm{H}, \mathrm{d}(7.5)$ \\
\hline 23 & $1.84,3 \mathrm{H}$, br.s & $1.89,3 \mathrm{H}, \mathrm{d}(1.0)$ \\
\hline 24 & $1.10,3 \mathrm{H}, \mathrm{d}(6.5)$ & $1.09,3 \mathrm{H}, \mathrm{d}(6.5)$ \\
\hline \multirow[t]{2}{*}{25} & $2.32,1 \mathrm{H}, \mathrm{m}$ & $2.33,1 \mathrm{H}, \mathrm{m}$ \\
\hline & $2.68,1 \mathrm{H}, \mathrm{m}$ & $2.68,1 \mathrm{H}, \mathrm{m}$ \\
\hline $8-\mathrm{OCH}_{3}$ & $3.31,3 \mathrm{H}, \mathrm{s}$ & $3.31,3 \mathrm{H}, \mathrm{s}$ \\
\hline $2^{\prime}$ & $3.70,1 \mathrm{H}, \mathrm{dd}(9.0,4.0)$ & $3.74,1 \mathrm{H}, \mathrm{m}$ \\
\hline \multirow[t]{2}{*}{$3^{\prime}$} & $2.96,1 \mathrm{H}, \mathrm{dd}(14.5,9.0)$ & $2.95^{*}, 1 \mathrm{H}, \mathrm{m}$ \\
\hline & $3.22,1 \mathrm{H}, \mathrm{dd}(14.5,4.0)$ & $3.34^{b}, 1 \mathrm{H}, \mathrm{m}$ \\
\hline
\end{tabular}

${ }^{a}$ Signals were assigned with aid of ${ }^{1} \mathrm{H}-{ }^{1} \mathrm{H}$ COSY, HMQC, and gHMBC experiments. *Overlapped signals. ${ }^{b}$ Overlapped with solvent peak. 
STable $13{ }^{1} \mathrm{H}$ NMR (500 MHz) spectral data of compounds 5 (NK30424A) and 6 (NK30424B) in $\mathrm{D}_{2} \mathrm{O}$

\begin{tabular}{|c|c|c|c|c|}
\hline Position & NK30424A ${ }^{a}$ & $\mathbf{5}^{b}$ & NK30424B $^{a}$ & $6^{b}$ \\
\hline \multirow[t]{2}{*}{2} & $2.67,1 \mathrm{H}, \mathrm{dd}(17.4,11.8)$ & $2.67,1 \mathrm{H}, \mathrm{dd}(17.5,12.0)$ & $2.52,1 \mathrm{H}, \mathrm{dd}(15.4,10.2)$ & $2.52,1 \mathrm{H}, \mathrm{dd}(15.0,10.5)$ \\
\hline & $2.85,1 \mathrm{H}, \mathrm{dd}(17.4,3.2)$ & $2.85,1 \mathrm{H}, \mathrm{dd}(17.5,3.0)$ & $3.00,1 \mathrm{H}, \mathrm{dd}(15.4,2.8)$ & $3.00,1 \mathrm{H}, \mathrm{dd}(15.0,2.5)$ \\
\hline 3 & $3.34,1 \mathrm{H}, \mathrm{m}$ & $3.35,1 \mathrm{H}, \mathrm{m}$ & $3.20,1 \mathrm{H}, \mathrm{m}$ & $3.20,1 \mathrm{H}, \mathrm{m}$ \\
\hline \multirow[t]{2}{*}{4} & $1.87,1 \mathrm{H}, \mathrm{m}$ & $1.84,1 \mathrm{H}, \mathrm{m}$ & $1.58,1 \mathrm{H}, \mathrm{m}$ & $1.58,1 \mathrm{H}, \mathrm{m}$ \\
\hline & $2.11,1 \mathrm{H}, \mathrm{m}$ & $2.09,1 \mathrm{H}, \mathrm{m}$ & $1.87,1 \mathrm{H}, \mathrm{m}$ & $1.88,1 \mathrm{H}, \mathrm{m}$ \\
\hline \multirow[t]{2}{*}{5} & $2.15,1 \mathrm{H}, \mathrm{m}$ & $2.15,2 \mathrm{H}, \mathrm{m}$ & $2.21,1 \mathrm{H}, \mathrm{m}$ & $2.23,2 \mathrm{H}, \mathrm{m}$ \\
\hline & $2.13,1 \mathrm{H}, \mathrm{m}$ & & $2.27,1 \mathrm{H}, \mathrm{m}$ & \\
\hline 6 & $5.81,1 \mathrm{H}$, ddd $(16.0,6.4,6.4)$ & $5.82,1 \mathrm{H}, \mathrm{dt}(16.0,6.5)$ & $5.86,1 \mathrm{H}$, ddd $(16.2,7.4,7.4)$ & $5.86,1 \mathrm{H}, \mathrm{dt}(16.0,7.0)$ \\
\hline 7 & $5.48,1 \mathrm{H}, \mathrm{dd}(16.0,7.4)$ & $5.48,1 \mathrm{H}, \mathrm{dd}(16.0,7.0)$ & $5.49,1 \mathrm{H}, \mathrm{dd}(16.2,6.8)$ & $5.48,1 \mathrm{H}, \mathrm{dd}(16.0,7.0)$ \\
\hline 8 & $3.55,1 \mathrm{H}, \mathrm{dd}(9.4,7.4)$ & $3.55,1 \mathrm{H}, \mathrm{dd}(9.0,7.0)$ & $3.58,1 \mathrm{H}, \mathrm{dd}(9.4,6.8)$ & $3.59,1 \mathrm{H}, \mathrm{dd}(9.0,6.5)$ \\
\hline 9 & $3.75,1 \mathrm{H}, \mathrm{dd}(9.4,4.8)$ & $3.75,1 \mathrm{H}, \mathrm{dd}(9.0,6.0)$ & $3.75,1 \mathrm{H}, \mathrm{dd}(9.4,2.4)$ & $3.75,1 \mathrm{H}, \mathrm{dd}(9.0,3.0)$ \\
\hline 10 & $2.03,1 \mathrm{H}, \mathrm{m}$ & $2.03,1 \mathrm{H}, \mathrm{m}$ & $2.05,1 \mathrm{H}, \mathrm{m}$ & $2.04,1 \mathrm{H}, \mathrm{m}$ \\
\hline 11 & $4.94,1 \mathrm{H}, \mathrm{d}(2.4)$ & $4.94,1 \mathrm{H}, \mathrm{d}(2.5)$ & $5.09,1 \mathrm{H}$, br.d $(2.4)$ & $5.08,1 \mathrm{H}, \mathrm{d}(2.0)$ \\
\hline 13 & $5.26,1 \mathrm{H}$, br.d $(9.6)$ & $5.27,1 \mathrm{H}, \mathrm{d}(11.0)$ & $5.30,1 \mathrm{H}$, br.d $(9.6)$ & $5.30,1 \mathrm{H}$, br.d $(10.5)$ \\
\hline 14 & $3.63,1 \mathrm{H}, \mathrm{dq}(9.8,6.4)$ & $3.62,1 \mathrm{H}, \mathrm{dq}(10.0,6.5)$ & $3.64,1 \mathrm{H}, \mathrm{dq}(9.6,6.6)$ & $3.65,1 \mathrm{H}, \mathrm{dq}(10.0,6.5)$ \\
\hline 16 & $2.72,2 \mathrm{H}, \mathrm{m}$ & $2.74,2 \mathrm{H}, \mathrm{m}$ & $2.75,2 \mathrm{H}, \mathrm{m}$ & $2.74,2 \mathrm{H}, \mathrm{m}$ \\
\hline 17 & $4.19,1 \mathrm{H}, \mathrm{m}$ & $4.19,1 \mathrm{H}, \mathrm{m}$ & $4.20,1 \mathrm{H}, \mathrm{m}$ & $4.20,1 \mathrm{H}, \mathrm{m}$ \\
\hline \multirow[t]{2}{*}{18} & $1.50,1 \mathrm{H}, \mathrm{m}$ & $1.51,1 \mathrm{H}, \mathrm{m}$ & $1.51,1 \mathrm{H}, \mathrm{m}$ & $1.51,1 \mathrm{H}, \mathrm{m}$ \\
\hline & $1.60,1 \mathrm{H}, \mathrm{m}$ & $1.60,1 \mathrm{H}, \mathrm{m}$ & $1.61,1 \mathrm{H}, \mathrm{m}$ & $1.62,1 \mathrm{H}, \mathrm{m}$ \\
\hline 19 & $2.41,1 \mathrm{H}, \mathrm{m}$ & $2.42,1 \mathrm{H}, \mathrm{m}$ & $2.45,1 \mathrm{H}, \mathrm{m}$ & $2.43,1 \mathrm{H}, \mathrm{m}$ \\
\hline \multirow[t]{2}{*}{20} & $2.46,1 \mathrm{H}, \mathrm{m}$ & $2.46,1 \mathrm{H}, \mathrm{m}$ & $2.48,1 \mathrm{H}, \mathrm{m}$ & $2.50,1 \mathrm{H}, \mathrm{m}$ \\
\hline & $2.73,1 \mathrm{H}, \mathrm{m}$ & $2.72,1 \mathrm{H}, \mathrm{m}$ & $2.77,1 \mathrm{H}, \mathrm{m}$ & $2.78,1 \mathrm{H}, \mathrm{m}$ \\
\hline 22 & $0.98,3 \mathrm{H}, \mathrm{d}(7.2)$ & $0.99,3 \mathrm{H}, \mathrm{d}(7.0)$ & $1.00,3 \mathrm{H}, \mathrm{d}(7.4)$ & $1.00,3 \mathrm{H}, \mathrm{d}(7.0)$ \\
\hline 23 & $1.78,3 \mathrm{H}, \mathrm{d}(1.0)$ & $1.79,3 \mathrm{H}$, br.s & $1.83,3 \mathrm{H}, \mathrm{d}(1.2)$ & $1.82,3 \mathrm{H}$, br.s \\
\hline 24 & $1.15,3 \mathrm{H}, \mathrm{d}(6.6)$ & $1.15,3 \mathrm{H}, \mathrm{d}(6.5)$ & $1.16,3 \mathrm{H}, \mathrm{d}(6.6)$ & $1.16,3 \mathrm{H}, \mathrm{d}(7.0)$ \\
\hline \multirow[t]{2}{*}{25} & $2.45,1 \mathrm{H}, \mathrm{m}$ & $2.45,1 \mathrm{H}, \mathrm{m}$ & $2.47,1 \mathrm{H}, \mathrm{m}$ & $2.48,1 \mathrm{H}, \mathrm{m}$ \\
\hline & $2.80,1 \mathrm{H}, \mathrm{m}$ & $2.78,1 \mathrm{H}, \mathrm{m}$ & $2.80,1 \mathrm{H}, \mathrm{m}$ & $2.80,1 \mathrm{H}, \mathrm{m}$ \\
\hline $8-\mathrm{OCH}_{3}$ & $3.31,3 \mathrm{H}, \mathrm{s}$ & $3.32,3 \mathrm{H}, \mathrm{s}$ & $3.35,3 \mathrm{H}, \mathrm{s}$ & $3.35,3 \mathrm{H}, \mathrm{s}$ \\
\hline Cys-2' & $3.96,1 \mathrm{H}, \mathrm{dd}(9.6,4.4)$ & $3.97,1 \mathrm{H}, \mathrm{dd}(7.5,4.0)$ & $3.95,1 \mathrm{H}, \mathrm{dd}(7.8,4.0)$ & $3.95,1 \mathrm{H}, \mathrm{dd}(8.0,4.0)$ \\
\hline \multirow[t]{2}{*}{ Cys-3' } & $3.05,1 \mathrm{H}, \mathrm{dd}(14.6,9.6)$ & $3.06,1 \mathrm{H}, \mathrm{dd}(14.5,8.0)$ & $3.10,1 \mathrm{H}, \mathrm{dd}(14.2,7.8)$ & $3.10,1 \mathrm{H}, \mathrm{dd}(14.5,8.0)$ \\
\hline & $3.21,1 \mathrm{H}, \mathrm{dd}(14.6,4.4)$ & $3.22,1 \mathrm{H}, \mathrm{dd}(14.5,4.5)$ & $3.25,1 \mathrm{H}, \mathrm{dd}(14.2,4.0)$ & $3.24,1 \mathrm{H}, \mathrm{dd}(14.5,4.0)$ \\
\hline
\end{tabular}

${ }^{a}$ NMR spectral data of NK30424A and NK30424B listed here were taken from literature (J. Antibiot. 2001, 54, 1111-

1115.). ${ }^{b}$ Signals were assigned with aid of ${ }^{1} \mathrm{H}-{ }^{1} \mathrm{H}$ COSY, HMQC, and gHMBC experiments in this study. 
STable $14{ }^{13} \mathrm{C}$ NMR (125 MHz) spectral data of compounds 5 (NK30424A) and 6 (NK30424B) in $\mathrm{D}_{2} \mathrm{O}$, and 44 and 45 in $\mathrm{MeOH}-d_{4}$

\begin{tabular}{|c|c|c|c|c|c|c|}
\hline Position & NK30424A $A^{a}$ & $\mathbf{5}^{b}$ & NK30424B ${ }^{a}$ & $6^{b}$ & $44^{b}$ & $45^{b}$ \\
\hline 1 & 173.2 & 172.5 & 172.9 & 172.7 & 171.7 & 171.2 \\
\hline 2 & 39.4 & 38.9 & 41.9 & 41.4 & 39.5 & 43.1 \\
\hline 3 & 41.6 & 41.0 & 40.5 & 40.0 & 41.3 & 41.8 \\
\hline 4 & 31.9 & 31.2 & 34.1 & 33.6 & 31.7 & 34.8 \\
\hline 5 & 29.1 & 28.6 & 28.7 & 28.2 & 29.0 & 29.4 \\
\hline 6 & 137.9 & 137.4 & 135.7 & $135.3^{*}$ & 137.5 & 135.4 \\
\hline 7 & 128.4 & 127.9 & 131.1 & 130.6 & 130.4 & 133.4 \\
\hline 8 & 83.2 & 82.7 & 82.9 & 82.4 & 84.6 & 84.0 \\
\hline 9 & 73.2 & 72.8 & 73.4 & 72.8 & 73.1 & 73.1 \\
\hline 10 & 39.0 & 38.5 & 39.1 & 38.6 & 39.4 & 39.8 \\
\hline 11 & 80.3 & 79.8 & 80.9 & 80.5 & 82.0 & 81.4 \\
\hline 12 & 135.0 & 135.3 & 135.4 & $135.3^{*}$ & 135.5 & 135.8 \\
\hline 13 & 126.6 & 126.4 & 127.1 & 126.5 & 128.6 & 129.1 \\
\hline 14 & 46.7 & 46.3 & 46.8 & 46.2 & 47.1 & 47.1 \\
\hline 15 & 216.2 & 215.7 & 216.0 & 215.8 & 213.5 & 213.6 \\
\hline 16 & 48.6 & 48.1 & 48.6 & 48.1 & 41.3 & 41.3 \\
\hline 17 & 65.4 & 64.9 & 65.3 & 64.3 & 21.5 & 21.5 \\
\hline 18 & 41.5 & 41.1 & 41.5 & 41.0 & 35.3 & 35.3 \\
\hline 19 & 27.3 & 26.9 & 27.4 & 26.9 & 31.4 & 31.4 \\
\hline 20 & 38.1 & 37.6 & 38.1 & 37.6 & 38.6 & 38.7 \\
\hline 21 & 177.5 & $177.1^{*}$ & 177.5 & 176.9 & 175.8 & 175.8 \\
\hline 22 & 11.6 & 11.1 & 11.3 & 10.8 & 11.8 & 11.6 \\
\hline 23 & 14.5 & 14.0 & 14.4 & 13.9 & 13.9 & 14.4 \\
\hline 24 & 16.0 & 15.5 & 15.9 & 15.4 & 16.4 & 16.3 \\
\hline 25 & 37.1 & 36.5 & 37.0 & $36.6^{*}$ & 38.6 & 38.7 \\
\hline 26 & 177.4 & $177.0^{*}$ & 177.4 & $176.9^{*}$ & $175.8^{*}$ & $175.8^{*}$ \\
\hline $8-\mathrm{OCH} 3$ & 56.6 & $56.1^{*}$ & 57.0 & $56.5^{*}$ & $57.1^{*}$ & $57.1^{*}$ \\
\hline $1^{\prime}$ & 177.4 & 177.1 & 177.4 & $177.0^{*}$ & $175.8^{*}$ & $175.8^{*}$ \\
\hline 21 & 56.6 & $56.1^{*}$ & 57.0 & $56.5^{*}$ & $56.8^{*}$ & $56.8^{*}$ \\
\hline $3^{\prime}$ & 37.1 & 36.6 & 37.0 & $36.6^{*}$ & 32.8 & 33.2 \\
\hline
\end{tabular}

${ }^{a}$ NMR spectral data of NK30424A and NK30424B listed here were taken from literature (J. Antibiot. 2001, 54, 11111115). ${ }^{b}$ Signals were assigned with aid of ${ }^{1} \mathrm{H}-{ }^{1} \mathrm{H}$ COSY, HMQC, and gHMBC experiments. *Overlapped signals or signals that could be interchangeable. 
SFigure 1. HPLC-UV (PDA)-ESI-MS analyses of resin extracts from fermentations of strain S. platensis with 10 and its eight congeners, 12-19, shown as distinct peak. (A) HPLC profile with UV detection at $205 \mathrm{~nm}$. (B) Total ion chromatograms (TIC) from LC-ESI-MS (+). (C) TIC from LC-ESI-MS (-). (D) LC-ESI-MS (-) selected for $\mathrm{amu}=490$, corresponding to 16. Peak identification: 10 (isomigrastatin), 12 (16, 17-didehydro-isomigrastatin), 13 (17-hydroxy-isomigrastatin), 14 (8-desmethyl-isomigrastatin), 15 (16, 17-didehydro-8-desmethyl-isomigrastatin), 16 (17-hydroxy-8-desmethyl-isomigrastatin), 17 (8-desmethoxy-isomigrastatin), 18 (16, 17-didehydro-8-desmethoxyisomigrastatin), 19 (17-hydroxy-8-desmethoxy-isomigrastatin).

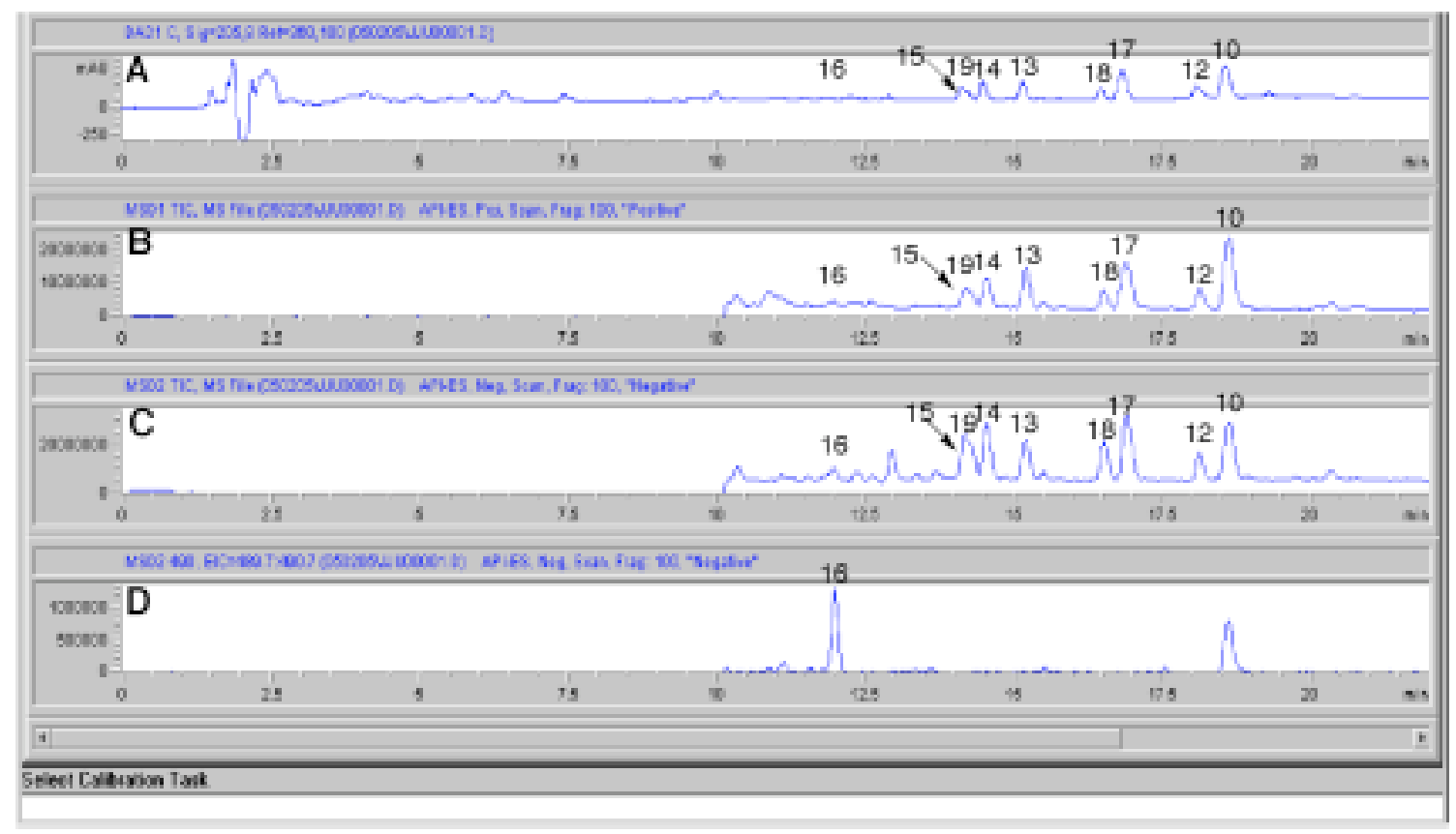


SFigure 2. Selected COSY (bold) and $g \mathrm{HMBC}$ (arrow) correlations observed in compounds 12-15 and 17-19

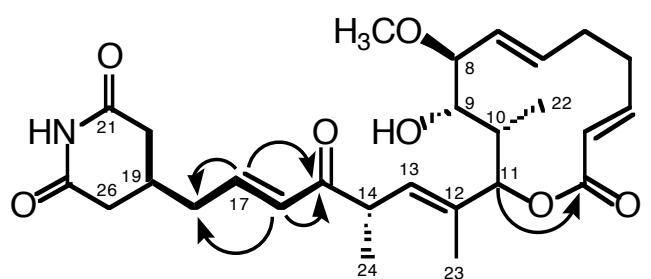

12

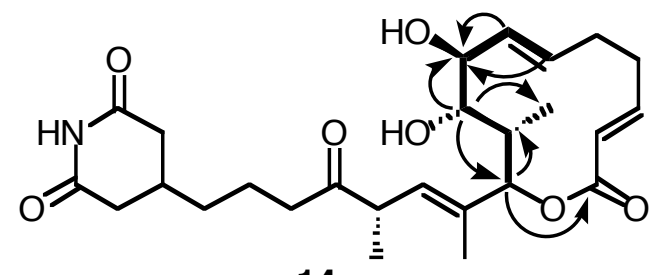

14

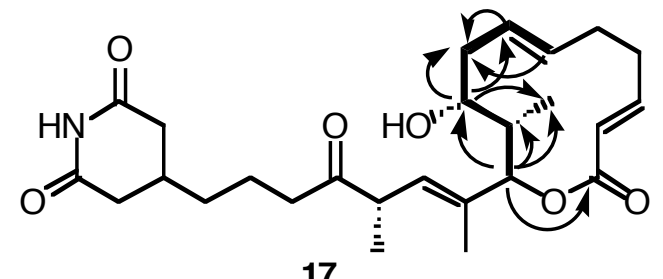

17

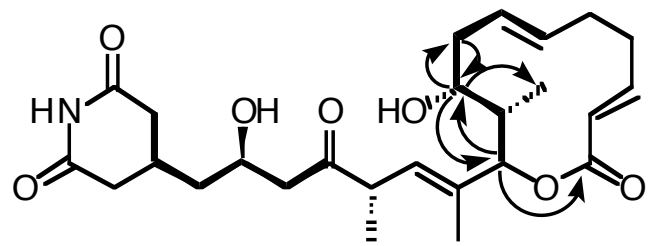



13

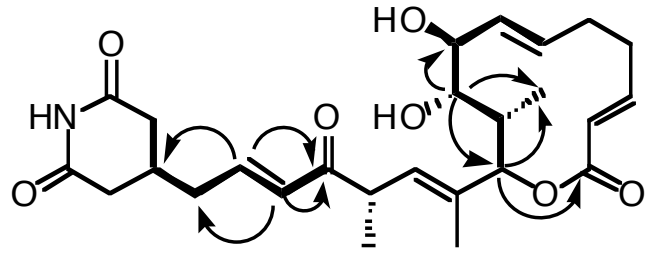

15



18 
SFigure 3. HPLC chromatograms of purified 12-14 and 17-19, together with their corresponding $\mathrm{H}_{2} \mathrm{O}$-mediated rearrangement products. (A), products of 10; (B), pure 12; (C), products of 12; (D), pure 13; (E), products of 13; $(\mathrm{F})$, pure 14; $(\mathrm{G})$, products of 14; $(\mathrm{H})$, pure 17; (I), products of 17; $(\mathrm{J})$, pure 18; $(\mathrm{K})$, products of 18; (L), pure 19; (M), products of 19. Peak identification: see Stable 4.

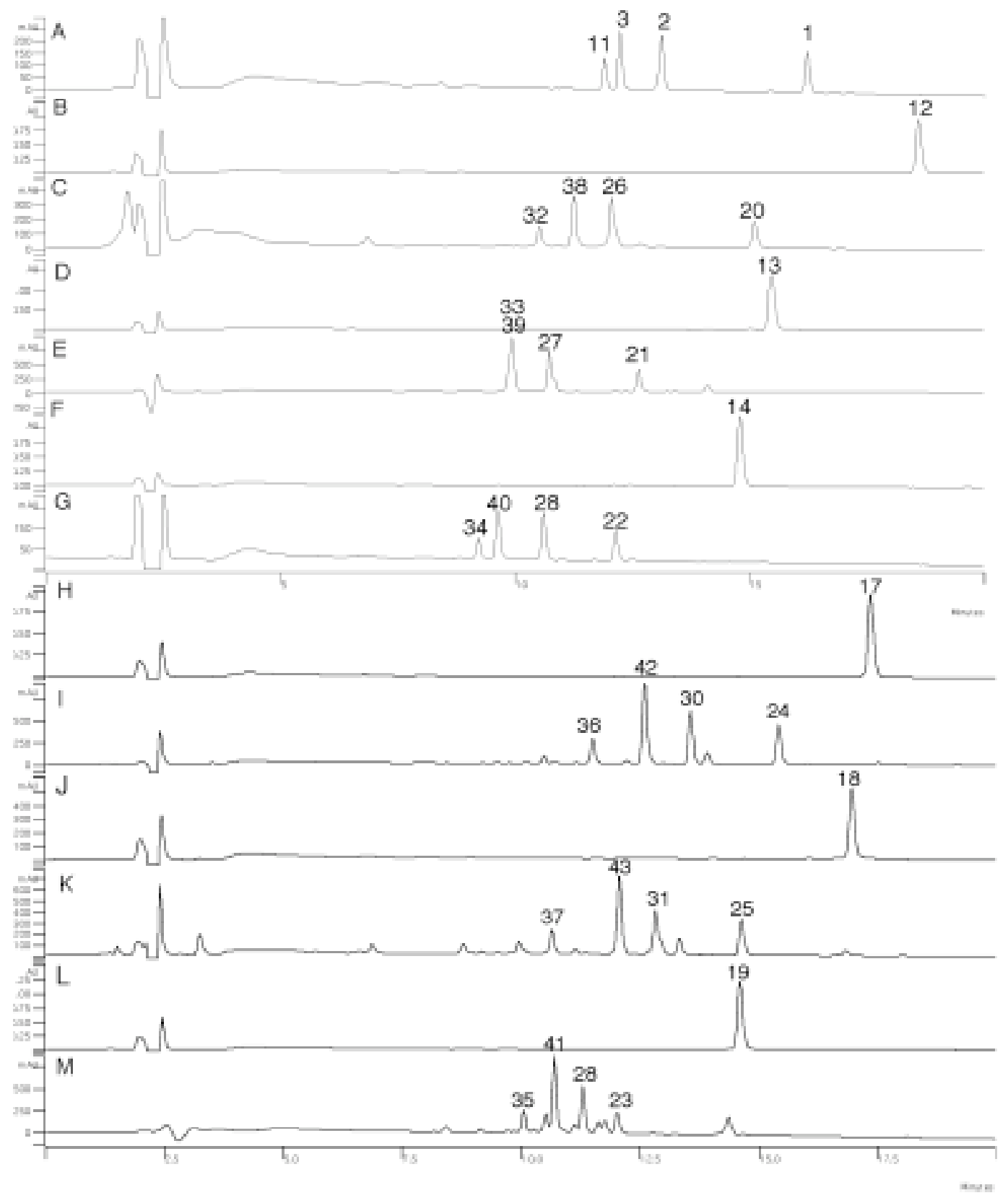


SFigure 4. Selected COSY (bold) and gHMBC (arrow) correlations observed in compounds 20-25
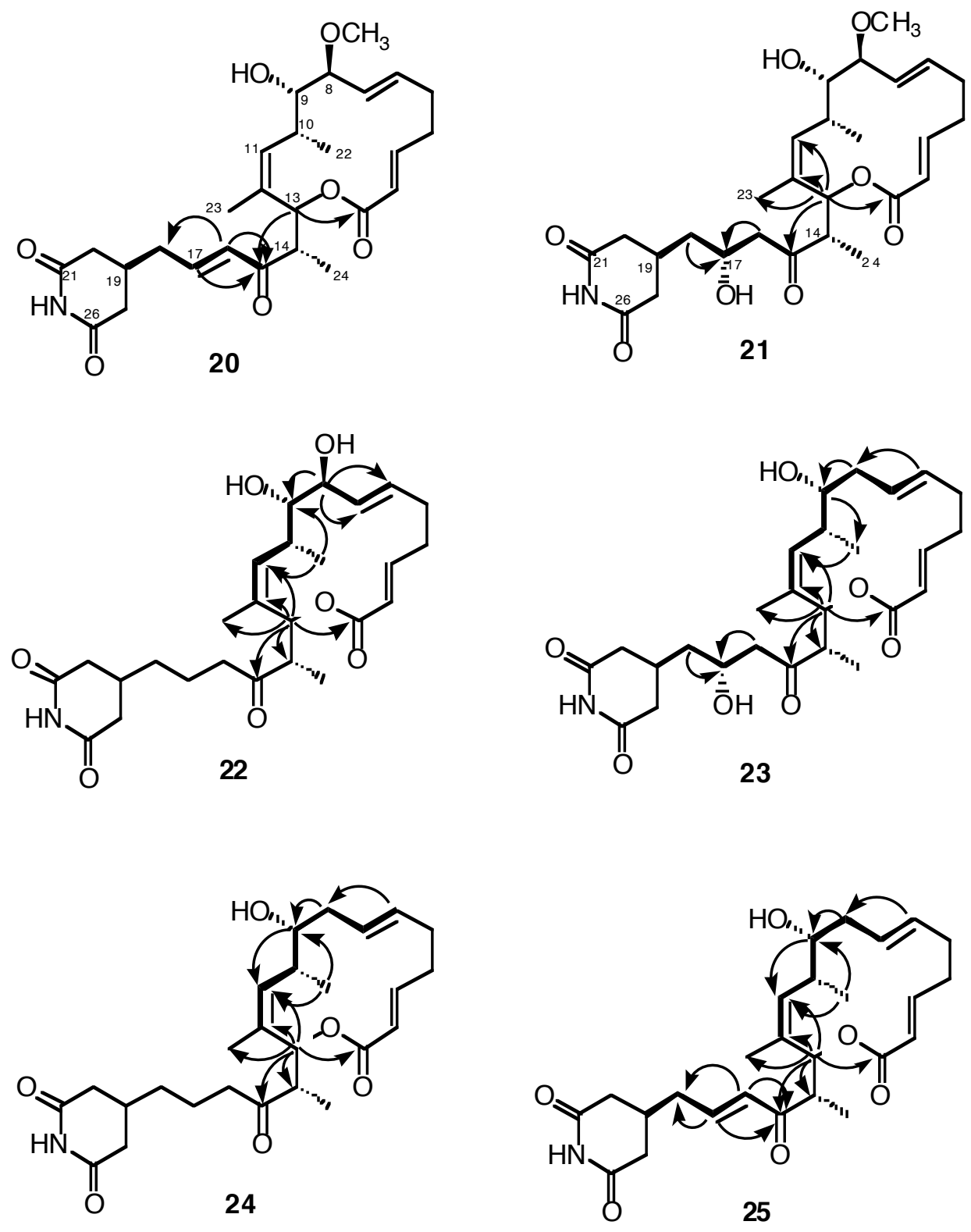
SFigure 5. HPLC chromatograms of products resulted from L-cysteine 1, 4-Michael addition of $\mathbf{1 0}$ (A and F), 13 (B and $\mathrm{G}), 14(\mathrm{C}), \mathbf{1 7}(\mathrm{D})$ and $19(\mathrm{E})$. While panels $\mathrm{A}-\mathrm{G}$ were developed with a linear gradient of $15 \% \mathrm{CH} \mathrm{CN}$ to $80 \% \mathrm{CH}_{3} \mathrm{CN}$ in $\mathrm{H}_{2} \mathrm{O}$ containing $0.1 \%$ HOAc over $20 \mathrm{~min}$, panels $\mathrm{F}$ and $\mathrm{G}$ were developed with a linear gradient of $20 \% \mathrm{MeOH}$ to $80 \% \mathrm{MeOH}$ in $\mathrm{H}_{2} \mathrm{O}$ over 20 min.

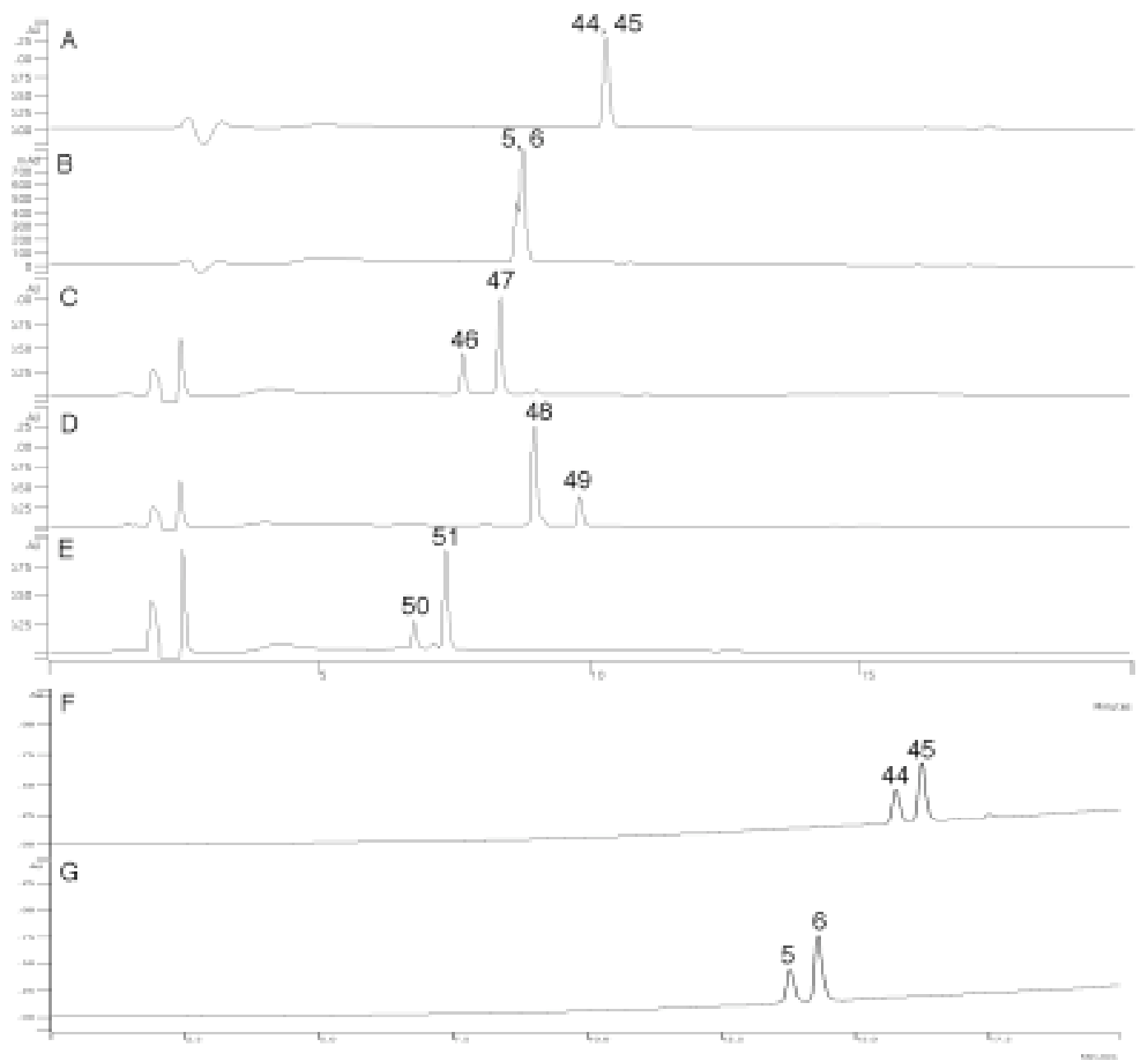




\section{References}

1. Ju, J.; Lim, S.-K.; Jiang, H.; Shen, B. J. Am. Chem. Soc. 2005, 127, 1622-1623.

2. Nakamura, N.; Takahashi, Y.; Naganawa, H.; Nakae, K.; Imoto, M.; Shiro, M.; Matsumura, K.; Watanabe, H.; Kitahara, T. J. Antibiot. 2002, 55, 442-444.

3. Santi, D. V. Kosan Biosciences, Inc., Hayward, CA, Determination of the relative stereochemistry of isomigrastation by X-ray crystallography. Personnel communication.

4 (a) Allen, M. S.; Becker, A. M.; Rickards, R. W. Aust. J. Chem. 1976, 29, 673-679. (b) Jeffs, P. W.; McWilliams, D. J. Am. Chem. Soc. 1981, 103, 6185-6192. (c) Kim, B. S.; Moon, S. S.; Hwang, B. K. J. Agric. Food Chem. 1999, 47, 3372-3380 and references cited therein.

5 (a) Takayasu, Y.; Tsuchiya, K.; Aoyama, T.; Sukenaga, Y. J. Antibiot. 2001, 54, 1111-1115. (b) Takayasu, Y.; Tsuchiya, K.; Sukenaga, Y. J. Antibiot. 2002, 55, 337-340. 